\title{
Genital Scars
}

Ursula Mirastschijski

\section{Contents}

\subsection{Epidemiology and Etiology of Genital Wounds - 406}

\subsection{Genital Skin Anatomy and Microstructure - 408}

47.2.1 Development of Genital Organs and Homology Between Sexes - 408

47.2.2 Anatomy of Male and Female Genitalia - 408

47.2.3 Microstructure of the Genital Skin - 408

47.3 Pathophysiology of Genital Wound Healing, Lymphedema and Scarring - 410

47.3.1 Skin Architecture and Biomechanics - 410

47.3.2 Moist Environment and Bacterial Colonialization - 412

47.3.3 Hormonal Influences -413

47.4 Acute Wound Repair of Genital Skin After Trauma - 415

47.5 Chronic Inflammatory Diseases of the External Genitalia and Tissue Fibrosis - 416

47.5.1 Lichen Sclerosus et Atrophicus/Balanitis Xerotica Obliterans - 416

47.5.2 Behçet's Disease - 418

47.5.3 Chronic Inflammation due to Foreign Body Reaction - 418

47.5.4 Congenital and Acquired Genital Lymphedema and Tissue Fibrosis -418

47.6 Treatment of Genital Wounds and Scars - $\mathbf{4 1 8}$

47.6.1 Treatment of Acute Wounds and Tissue Defects -420

47.6.2 Treatment of Genital Wounds and Scars After Burn Injury - 420

47.6.3 Gender Reassignment Surgery - 421

47.6.4 Treatment of Chronic Genital Skin Diseases - 423

47.6.5 Lymphedema Treatment -423

47.7 Postoperative Management for Scar Prevention - 423

47.8 Conclusion -424

References -424 


\section{Background}

Excessive scarring of the genitalia is uncommon despite the fact that approximately $30 \%$ of men are circumcised worldwide with minor complication rates and no mention of scarring. After burn injury, severe scarring is commonly seen in the perineal or suprapubic area but rarely occurs to the outer genital organs. Skin anatomy, inflammatory response, and hormonal metabolism differ between the genitals and the extragenital skin and might therefore account for differences in wound healing and scarring. Owing to the high regenerative potential of genital skin, the management of genital wounds aims at the stabilization of the local tissue with infection control and demarcation of necrotic tissue. Reconstruction of tissue defects and scars comprises plastic surgical skin tissue transfer, including flap surgery and the restoration of the urinary and sexual function in an interdisciplinary context.

- The objectives of this chapters are as follows

- To give an overview on the epidemiology and cause of genital scarring

- To point out specific features of genital skin anatomy

- To inform on the pathophysiology on skin wound healing, lymphology, and scarring of the outer genitals in women and men

- To describe management of genital wounds and tissue defects

- To give an overview on conservative and surgical treatment of genital wounds and scars

\subsection{Epidemiology and Etiology of Genital Wounds}

Since the ancient times, male circumcisions have been practiced by many communities mainly as a purity or religious ritual (• Fig. 47.1). Female genital mutilation (FGM)/cutting is still a common practice in many African countries, no matter the religious background of the people. Little is known on the incidence and severity of scarring in the genital area despite the fact that $30 \%$ of all men on the earth are circumcised [37].

Aside from circumcisions and ritual cuttings, other types of injuries, infections, tumors, skin diseases, and malformations can lead to abnormal wound healing and scarring of the genital skin. Due to the multitude of causes for genital trauma with subsequent scarring, a general incidence for genital scars is difficult to provide. As a consequence, I will first describe different origins for genital tissue defects with special focus on cutaneous wound healing and scarring of the outer genitalia, that is, the vulva, the scrotum, and the penis. For wound repair of the urinary system or the vagina and uterus, I would like to refer to the corresponding urological or gynecological literature and textbooks.

\section{- Causes for genital scarring and fibrosis}

- Trauma, for example, burns, injuries to the pelvic area, autoerotic injuries, genital self-mutilation

- Sequelae of any type of infections, for example, Hidradenitis suppurativa/acne inversa, Fournier gangrene, viral infections, and sexually transmitted diseases

- Fig. 47.1 Ritual act of circumcision: relief in the tomb of Ankhmahor at Saqqara (sixth dynasty, $2345 B C$; (C) CC BY-SA 3.0). This work is licensed under a Creative Commons Attribution-ShareAlike 3.0 Unported License

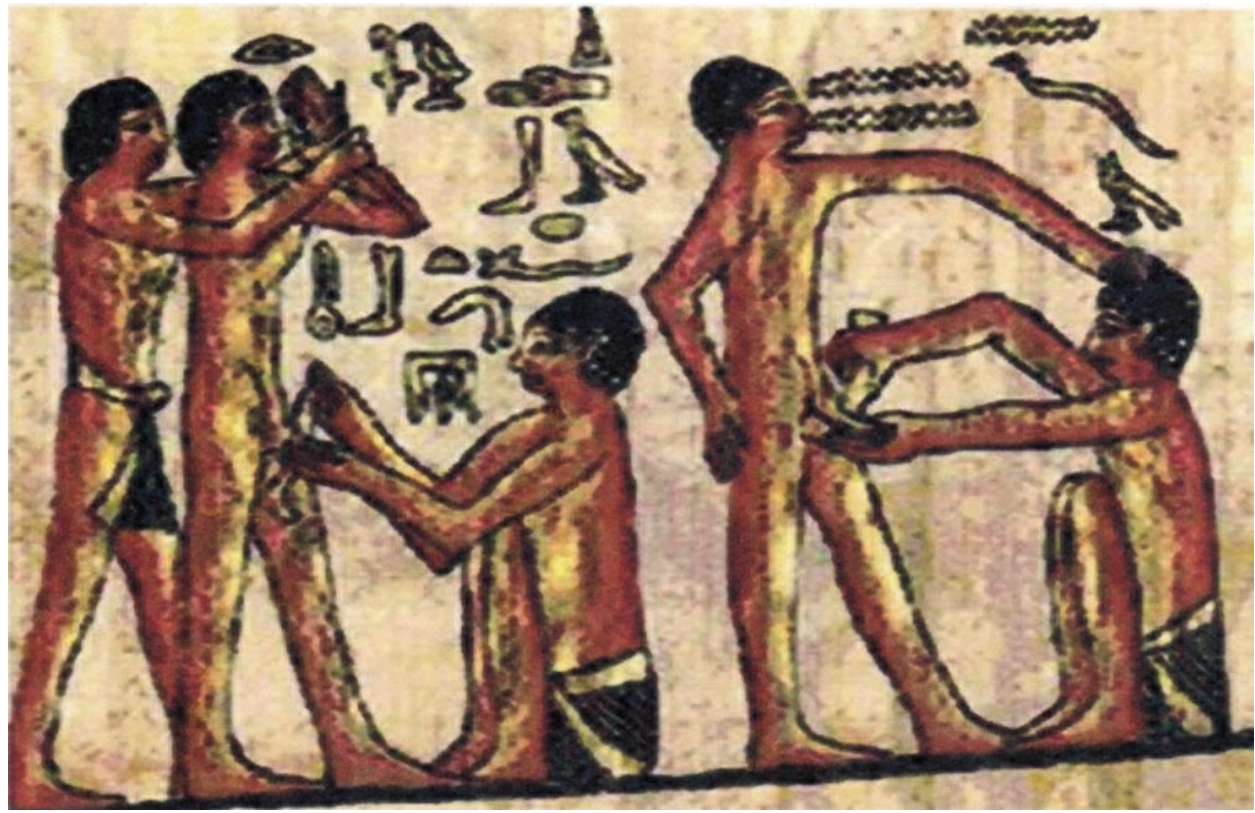


- Dermatological diseases, for example, various inflammatory autoimmune diseases (e.g., Behçet's syndrome or Crohn's disease with ulcerations, pyoderma gangraenosum), bullous skin diseases, lichen sclerosus et atrophicus (LSC), lichen planus

- Religiously/culturally motivated, for example, circumcisions, FGM/-cutting, or self-inflicted procedures, for example, piercings, tattoos, foreign body insertion

- Iatrogenic/surgical interventions, for example, aesthetic surgery, cosmetic procedures, including foreign body application; circumcision for phimosis; treatment of malformations; genital reassignment surgery

- Tumors followed by oncological surgery with/without radiation therapy

- Lymphatic disorders: congenital (Milroy's or Meigs' disease) or acquired (e.g., after tumor surgery, lymph node excision, irradiation; infectious: filariasis)

The literature search for causes of genital wounds that result in scarring yields some information on burns or combat injuries with concomitant affection of the genital organs. The incidence of burn injury to the genitalia is rare with around 1.5\% [15] but associated with a higher mortality rate with $17 \%$ in comparison to nongenital burns $(4.7 \%)$ [12]. In contrast to perineal and inguinal scar contractures that are a common sequela after burns to the lower abdomen and groin area, excessive scarring is rarely attributed to the outer genital organs (- Fig. 47.2).

The shift from high velocity to more explosive weapons during the end of the twentieth century and the use of improvised explosive devices resulted in more genital injuries in military conflicts than noticed before [1]. Genitourinary trauma accounted for only $5.3 \%$ of all

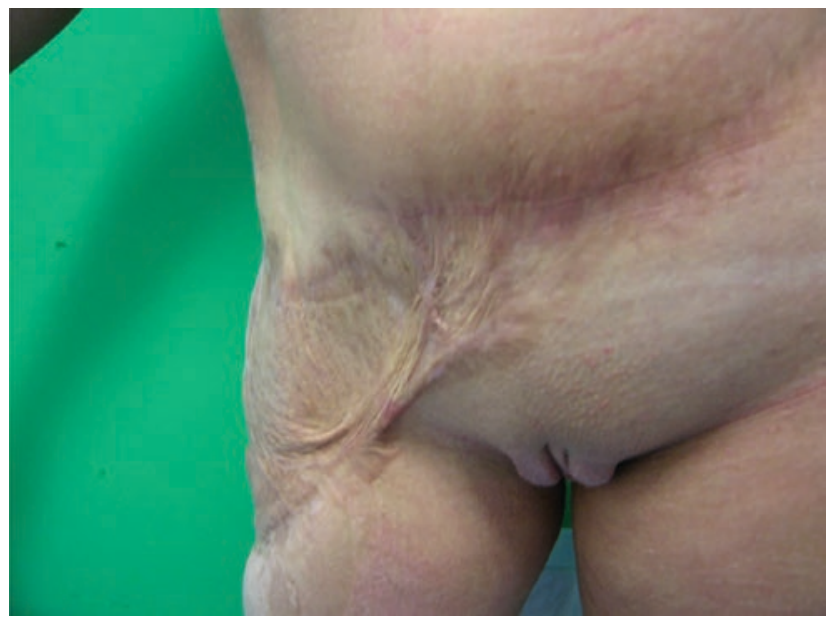

- Fig. 47.2 Inguinal scar contracture with impairment of the abduction of the right leg but without involvement of the big labia after severe burn injury combat-related injuries being mostly associated with severe polytraumatic incidents $(62.1 \%)$. There are no reports on scarring after this type of injury.

Infections are quite common in the genital area. With several body orifices being anatomically located in close relation, a multitude of commensal microbia is constantly present. In case of small lesions, lacerations, or immune incompetence of the host, germs can penetrate into deeper tissue layers and cause severe infections, for example, abscesses or gangrenes with high mortality rates. Predisposed patients develop chronic infections of the sweat glands and hair follicles in the groin and genital area, also called hidradenitis suppurativa or acne inversa. Without appropriate treatment, they develop fistulas with recurrent infections and subsequent scarring to the perineal crease. The annual prevalence of hidradenitis suppurativa is around $1 \%$ with an estimate of 70 million patients worldwide [14].

Fournier gangrene is a life-threatening necrotizing fasciitis of the genitalia with an incidence of 1.6/100,000 patients that affects mostly men (10:1) [18]. The only sufficient cure is the radical surgical debridement of the entire infected and necrotic tissue with accompanying antibiotic treatment. Massive tissue losses can be the consequence with plastic surgical reconstruction after successful elimination of the infection. Because the tissue defects have a tendency to spread over the groin area as well, scar contractures are found as remnants of this type of genital infection (• Fig. 47.3).

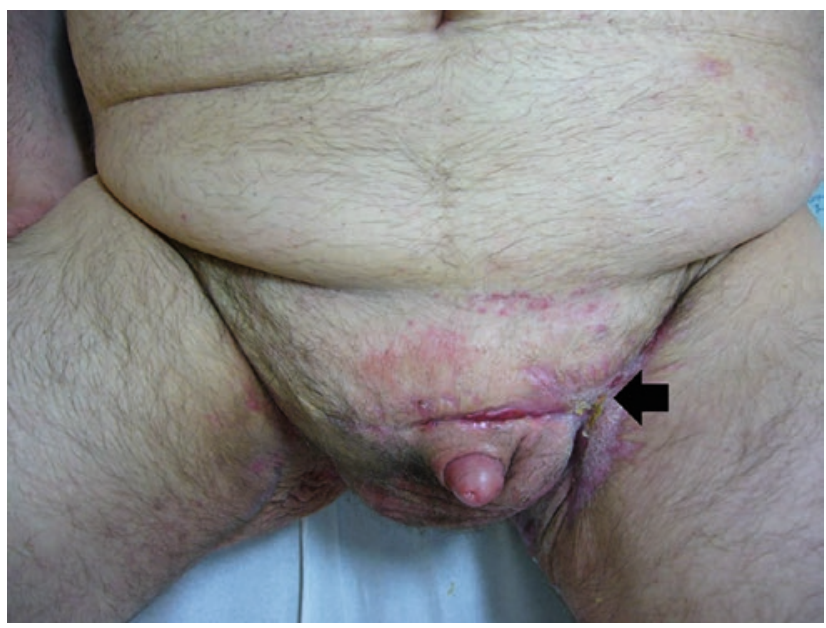

- Fig. 47.3 Inguinal hypertrophic scarring with scar contractures after hidradenitis suppurativa and recurrent inguinal infections that culminated into a Fournier gangrene with vast tissue excision and postoperative scarring. The resulting scar contractures impaired the abduction of the left leg. Please note the instable scar with recurrent ulceration between the prepubic area and the left inguinal crease adjacent to the contracture (arrow). Aside from severe scarring, a buried penis grade III is present. No scarring of the penile skin or glans but of the pubic skin and groin is present 
The incidence of autoerotic or self-inflicted genital injuries has not been determined but is extremely low and patients present sporadically. Genital lesions can derive from blunt, strangulating, or penetrating trauma and go as far as to incomplete or total amputations. Self-inflicted genital injuries can derive from neurotic, psychotic, and various other types of mental disorders or associated diseases and are seen in gender dysphoric conditions.

It appears that the genital skin tends more to chronic ulcers or fistulas seen in various dermatological diseases or infections than to healing with excessive scar formation. Despite reports on scarring after Behçet's syndrome, it seems that the genital skin heals with atrophic rather than hypertrophic scarring. Of note, excessive swelling of the outer genitalia is another feature that occurs typically after trauma or surgery and that differs to skin wound repair of other body areas. Genital lymphedema can be idiopathic and associated with congenital malformations but is also present after cancer therapy and infections, for example, filariasis. Chronic genital lymphedema can ultimately lead to severe fibrotic conditions and elephantiasis.

The genitalia differ in several regards from other body sites. Urogenital and anal orifices and the surrounding skin are colonized by resident microbia in a moist environment, there is abundant highly elastic skin around the external genital organs that is loosely fixed to the pelvic bone, and the cutaneous microstructure, inflammatory reaction, and hormonal responsiveness are different compared to other tissues. In the following sections, all these features and their influence on genital wound repair and scarring will be elucidated in detail.

\subsection{Genital Skin Anatomy and Microstructure}

For a better understanding why genitalia behave differently to skin from other body sites, the macro- and microstructure of the genital skin and organs, including lymphatics, are important and will be described in the following paragraphs. The knowledge of the anatomy is the prerequisite for the appropriate conservative and surgical treatment.

\subsubsection{Development of Genital Organs and Homology Between Sexes}

Female and male outer genitals derive from the same embryological origins with different development depending on the sex of the infant. The development of the external genitalia is presented in detail in - Fig. 47.4, which depicts the common origin of respec- tive anatomical entity at the embryonic stage and further differentiation into male and female genitalia during the fetal period. - Table 47.1 summarizes the homologous anatomical and microscopic structures.

\subsubsection{Anatomy of Male and Female Genitalia}

The main anatomical differences between genital and skin of other body areas are the lack of fat tissue to the scrotum, penis and labia minora, the absence of hair to the penile and small labia skin, and the reduced or missing cornified epidermal layer of the epithelium of the prepuce and the small labia. With regard to biomechanics, the genital skin is highly elastic and flexible because it lacks a firm attachment to underlying structures, for example, bones or cartilage. A subcutaneous smooth muscle layer, also called Dartos muscle or Tunica dartos that is found in the scrotum and big labia, is reminiscent of the subcutaneous carnosus muscle in fur bearing animals and enables a gliding between the skin and the underlying connective tissue. Of note, the anatomic relict of the carnosus muscle in humans is the Scarpa fascia that is found in most other parts of the body underneath the subcutaneous fat layer. The genitalia are devoid of fat and the Scarpa fascia. Instead, the Dartos fascia is found here. An illustration of the genital anatomy for both sexes is shown in $\bullet$ Figs. 47.5 and 47.6

\section{- Summary: Differences Between Genital and} Nongenital Skin

Genital skin differs from other regions:

- No subcutaneous fat tissue, no Scarpa fascia; instead tunica dartos with smooth muscle cells (scrotum and big labia) or dartos fascia with loose attachment of the skin (penis)

- No tight attachment of the skin to underlying bone or cartilage

- Little or no keratinizing epithelia-mucous surfaces of small labia, glans, and prepuce

- Reduced hair growth - skin of scrotum and big labia

- Moist environment due to mucous surfaces and a multitude of mucous secreting glands

- Constant microbial contamination - cutaneous, genitourinary, and intestinal flora

\subsubsection{Microstructure of the Genital Skin}

The skin is the largest organ of the human body that protects us against biological (e.g., microbial), chemical (e.g., acids, bases), physical (e.g., irradiation, pressure), thermal (heat, cold), and other threats, including exsic- 
a
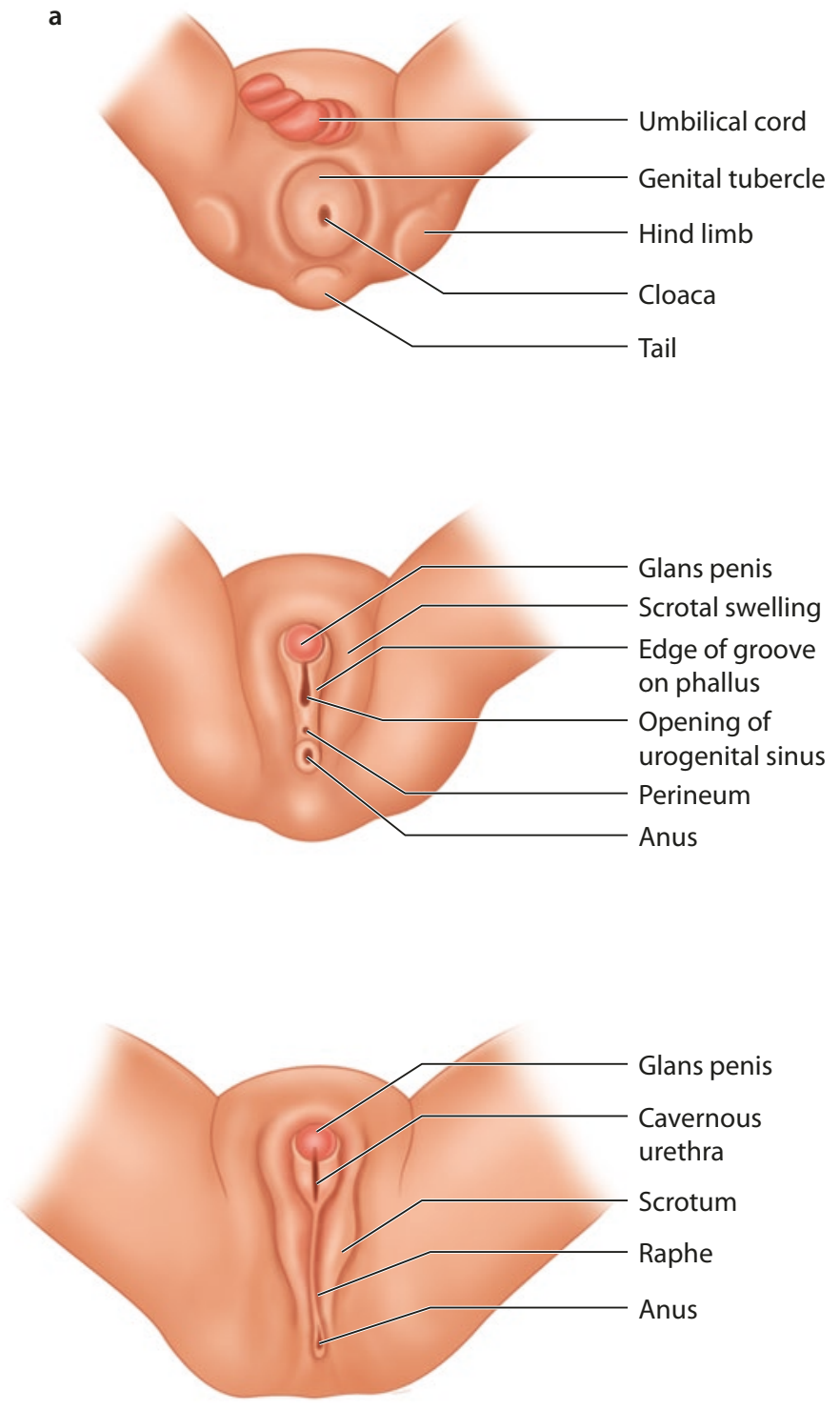

- Fig. 47.4 Development of the external genitalia in $\mathbf{a}$ men and $\mathbf{b}$ women b
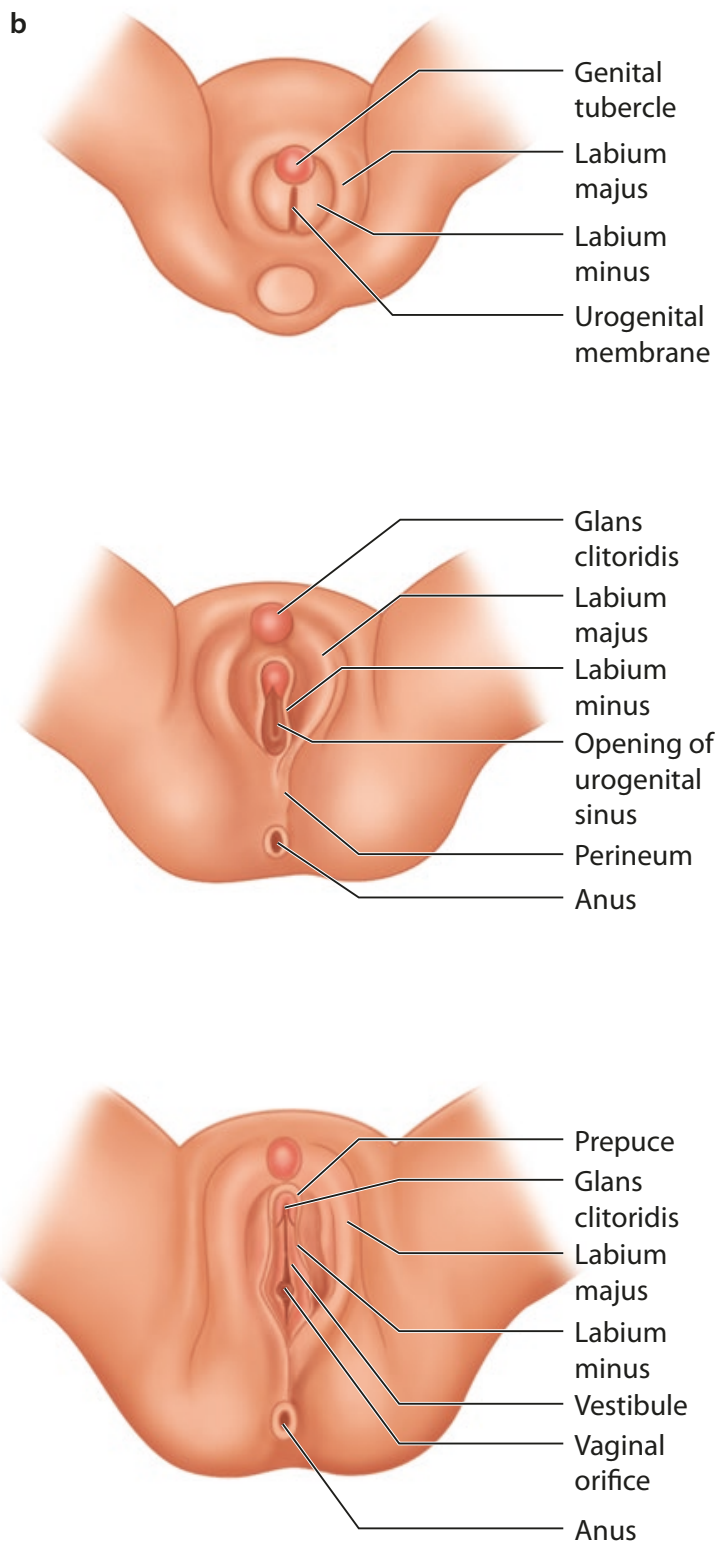

cation. We sense our environment by touching things and we are simultaneously protected by pain receptors in the skin. We regulate our body temperature via the cutaneous vasculature, and we communicate with other people via mimics or smell - all provided by our intact skin. To ensure its protective function, the skin possesses an intricate architecture that can vary depending on the body site, for example, eyelid, back, palms, oral cavity, or genitals. The general micro-structure of the skin comprises three different entities, that is, the epidermis, the dermis (cutis) consisting of the upper/papillary and the lower/reticular dermis, and the subcutaneous fat layer.
Epidermis and dermis are separated from each other by a basement membrane that is also the limit for vasculature. The epidermis is free of vessels and nourished by means of oxygen diffusion. The subcutaneous fat is separated from the deeper fat by a superficial fascia, called Scarpa fascia. In the genitalia, this superficial fascia is called Colles (women) or Dartos fascia (men). This anatomical structure is of importance because it serves as a fixation point between fat layers whereas it provides elasticity and sliding properties to the genital skin.

The cutaneous surface of moist environments is characterized by the absence of the cornified layer and 
Table 47.1 Homology of male and female genitalia

\begin{tabular}{|c|c|c|}
\hline Male & Female & Microscopic structure of the skin \\
\hline Glans penis & Glans clitoridis & Multilayered, nonkeratinizing epidermis, dermal tissue with abundant innervation \\
\hline Penile foreskin & Clitoral prepuce & $\begin{array}{l}\text { Outer face of foreskin: epidermis with cornified layer; } \\
\text { Inner face: nonkeratinizing epidermis; mucous epithelium; no subcutaneous fat tissue }\end{array}$ \\
\hline Frenulum penis & Frenula clitoridis (pair) & Nonkeratinizing, mucous epithelium, no fat tissue \\
\hline Penile shaft skin & Small labia & $\begin{array}{l}\text { Penis: epidermis with cornified layer } \\
\text { Labia: outer surface with thin cornified layer; inner surface: no cornified layer } \\
\text { Both sexes: no hair; no subcutaneous fat tissue; many elastic fibers; } \\
\text { Penis: highly flexible attachment to underlying tissue via Dartos fascia (fascia penis } \\
\text { superficialis) }\end{array}$ \\
\hline Scrotal skin & Big labia & $\begin{array}{l}\text { Hair bearing epidermis (labia: only outer surface), epidermal cornified layer } \\
\text { Labia: subcutaneous fat layer and smooth muscle cells } \\
\text { Scrotum: no fat, but contractile tunica dartos with smooth muscle cells and } \\
\text { myofibroblasts }\end{array}$ \\
\hline
\end{tabular}

hair follicles. Instead, different types of glands, for example, apocrine and eccrine, secrete fluids that moisturize the surface and protect the mucous epithelium (• Figs. 47.7, 47.8, and 47.9).

\subsection{Pathophysiology of Genital Wound Healing, Lymphedema and Scarring}

Cutaneous scarring with tissue fibrosis is the result of a postnatal wound healing process. The longer the duration and the excessive the inflammatory response in the healing course, the more likely is the development of aberrant scarring and severe tissue fibrosis. However, scar formation varies depending on the body site, the skin architecture and anchorage to underlying structures.

Little is known about the pathophysiological processes of genital cutaneous wound repair except for the general clinical statement that genital wounds heal fast, with enormous swelling and almost invisible scarring. In the following, I will describe features that are different between the genitalia and the skin of other areas of the body and that influence acute wound healing or chronic scarring (- Fig. 47.10). It is beyond the scope of this chapter to include urethral, vaginal, or anal epithelial repair; tissues that derive from different developmental origins and with differential healing behavior (e.g., ulcerations, adhesion or fistula formation) compared to genital skin.

\subsubsection{Skin Architecture and Biomechanics}

The genital skin has to master many challenges, for example, fast volume changes during sexual activity, sex steroid sensitivity with permanent hormonal changes, the presence of several body openings with constant commensal microbial presence, and infectious threats deriving from sexual contacts. In that context, it is breathtaking to understand the extraordinary adaption of the genital skin to its multiple tasks. To encounter aforementioned challenges, it is excellently equipped anatomically and physiologically to address specific features of the genital microenvironment.

Notably the male genital skin has to manage fast volume changes that occur during sexual activity and for thermal regulation of the testes. These physiological tasks are addressed by several means: (i) abundance of skin tissue on both the penile shaft and the scrotal sac, (ii) the Dartos fascia on the penile shaft and the Tunica Dartos with the Dartos muscle in the scrotum, and (iii) a high amount of elastic fibers in the dermis. In all three items, the genitalia differ from skin of other body areas that is firmly attached to the underlying structures by a rather immobile fat layer. High skin elasticity and abundance of tissue are the prerequisite for tension-free acute wound healing with unapparent scars - optimal repair conditions present in the genitalia. A drawback is the tendency of the outer genitals to enormous swelling and edema after surgery or trauma. The good side is that due to its elasticity and intricate lymphatics, the swelling of the genital tissue resolves as fast as it occurs in healthy subjects. 
Diaphragma urogenitale und M. sphincter urethrae externus

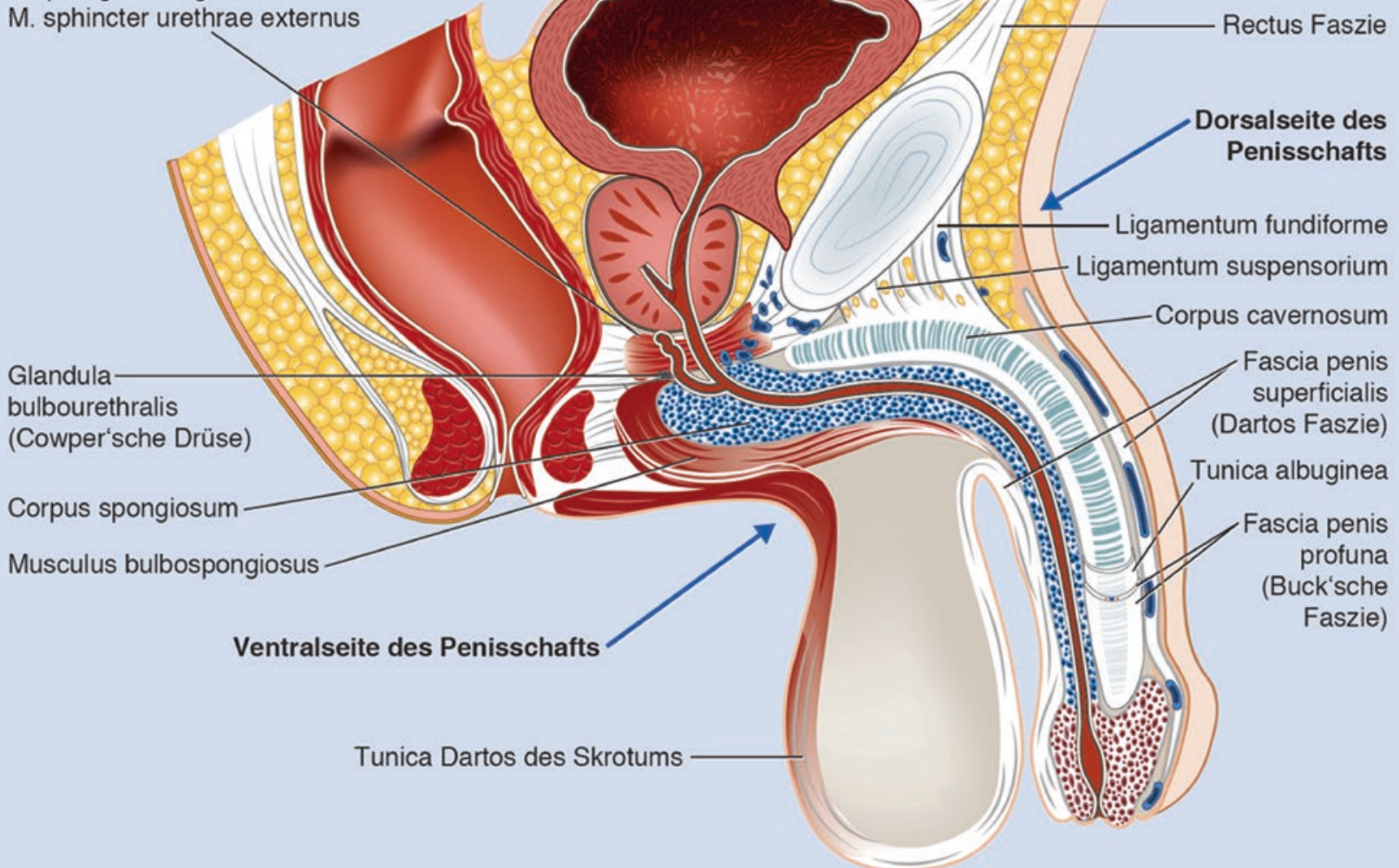

b

V. dorsalis profunda penis

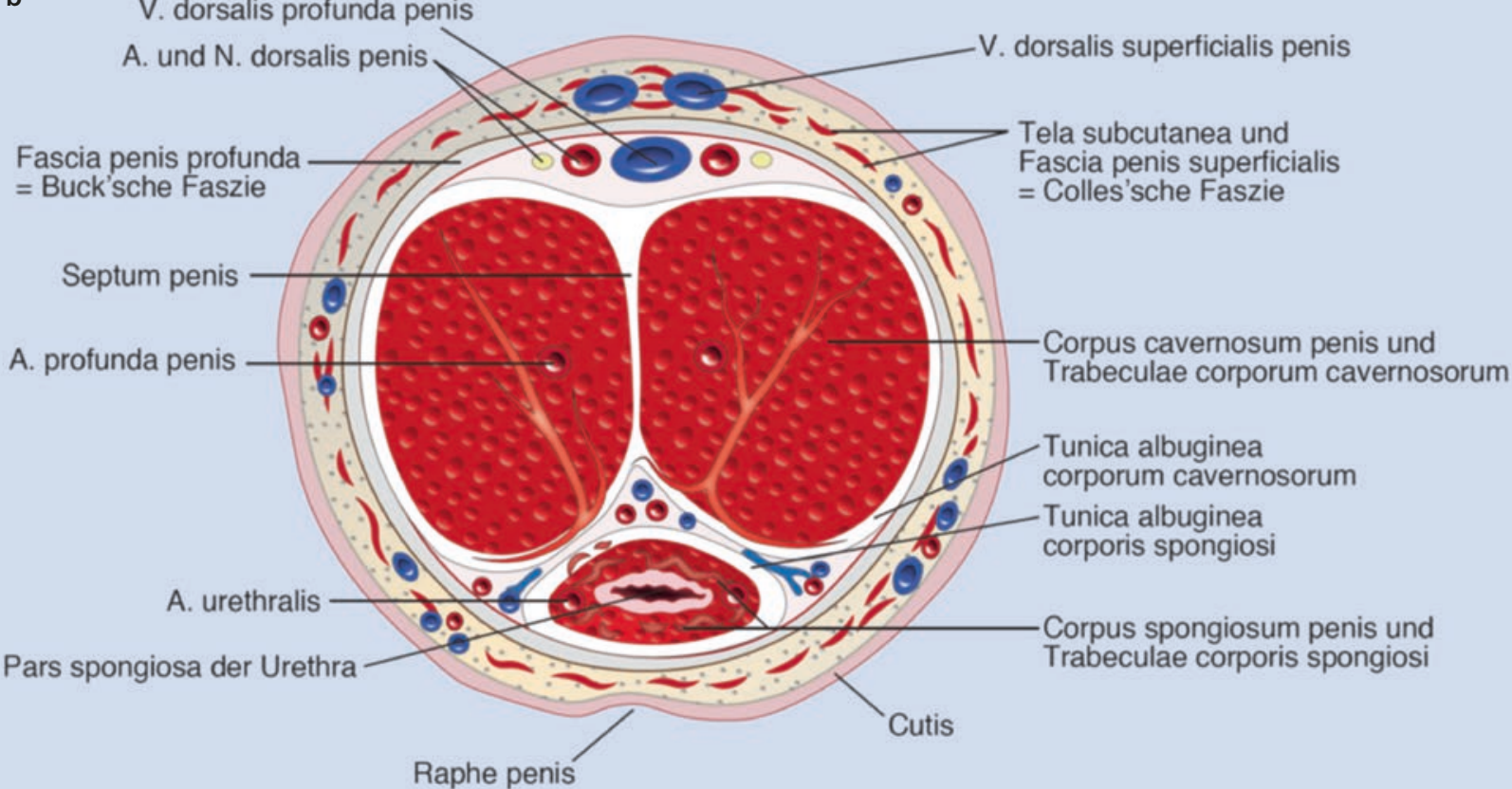

- Fig. 47.5 Anatomy of the male external genitalia. Of note, no fat tissue is present in the penis or scrotal tissue underneath the skin. (Source: Mirastschijski \& Remmel, Intimchirurgie, Springer Verlag, 2019) 


\subsubsection{Moist Environment and Bacterial Colonialization}

Urethral, vaginal, and anal orifices are transition zones between mucous membranes and keratinizing skin. As depicted previously, parts of the genitalia are covered

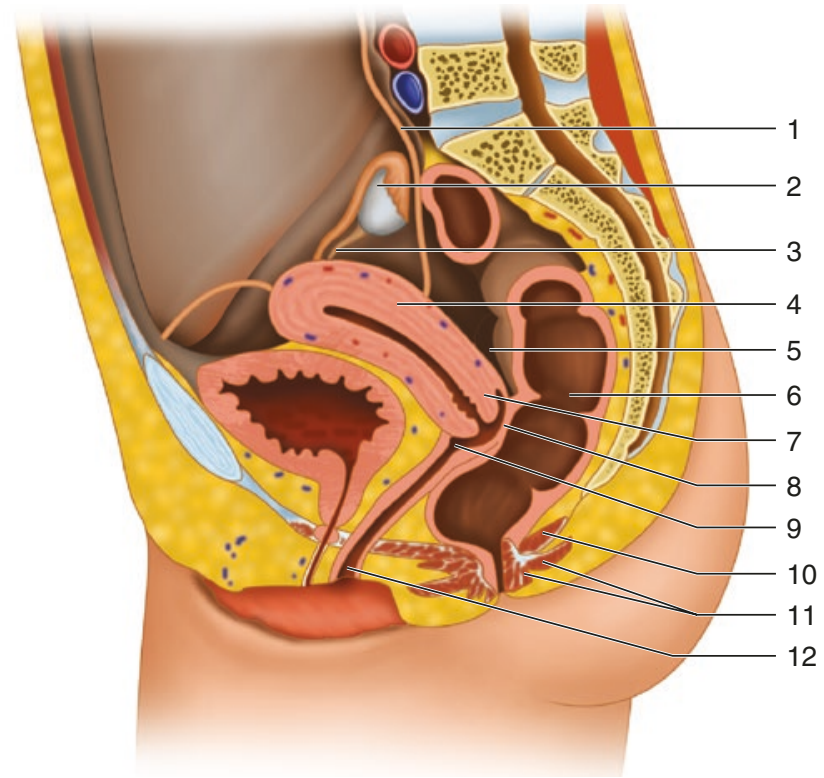

- Fig. 47.6 Anatomy of the female external genitalia by little or nonkeratinizing squamous epithelia. The secreted fluids of multiple glands prevent the exsiccation of mucous membranes and provide a moist microenvironment. It is an established fact that moist wound healing contributes to faster wound closure and reduced scarring.

The proximity of the genital skin to different orifices is Janus sided. Aside from the beneficial moist milieu, bacterial load and stringent body fluids such as urine bear constant threats to the fragile mucosal skin lacking the protective epidermal cornified layer. And again, the genital mucosal skin is well prepared to address both biological and chemical challenges. In contrast to other parts of the body, keratinocytes and fibroblasts of the

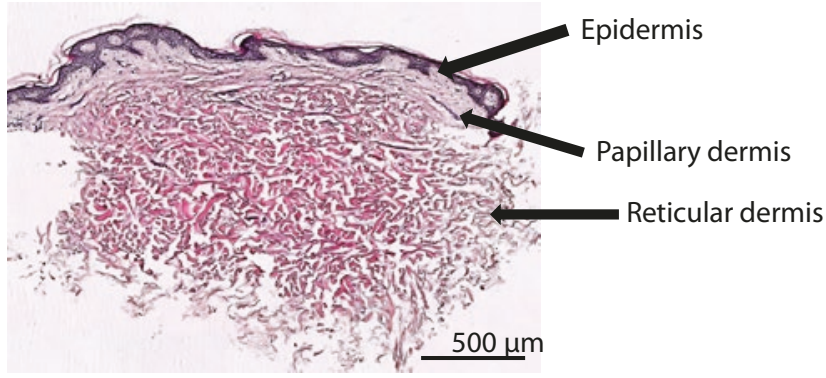

- Fig. 47.8 Histological section from the abdominal skin stained with hematoxylin-eosin. (By courtesy of Dr. D. Jiang and Dr. Y. Rinkevich, Helmholtz Center Munich. (C) All rights reserved)
Multilayered, non-keratinizing squamous epithelium

\section{Multilayered, keratinizing squamous epithelium}

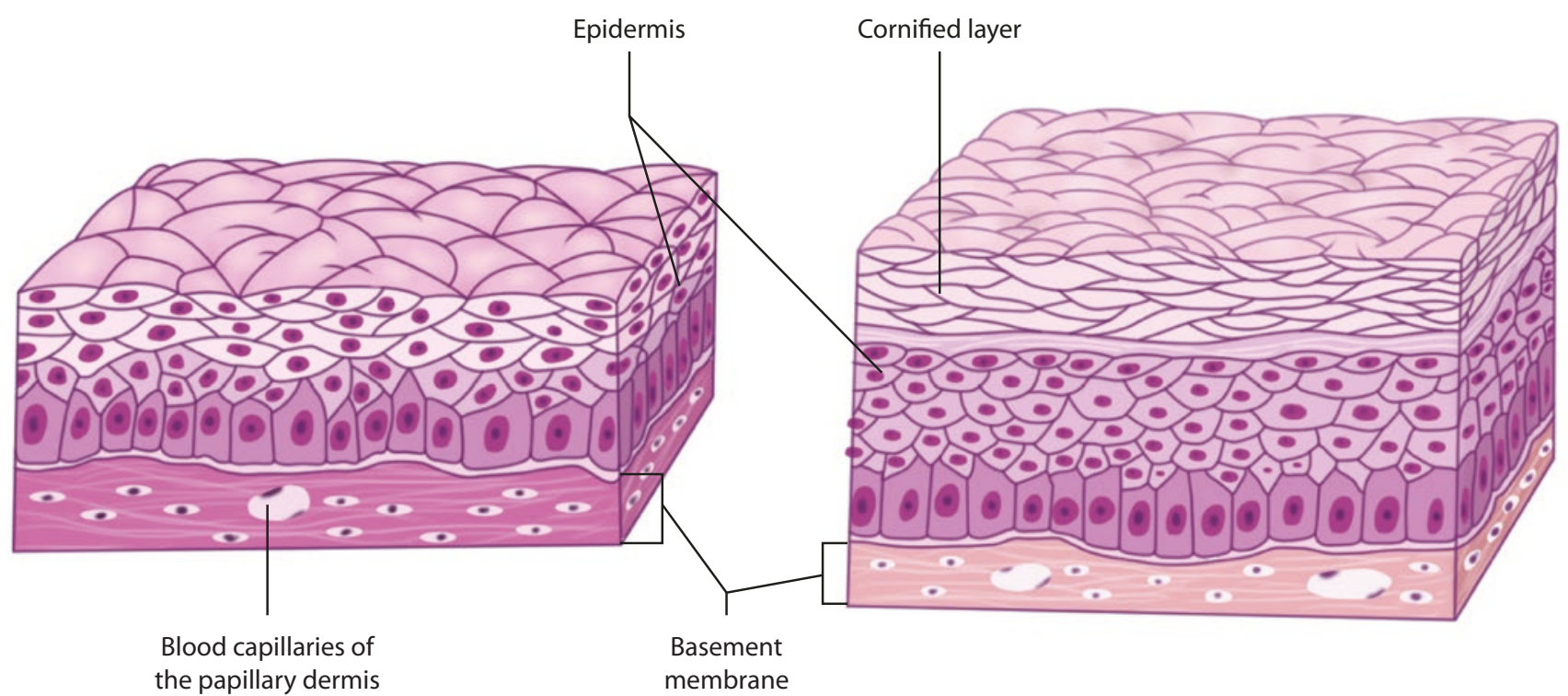

Skin type found in moist environments, e.g. glanspenis/clitoridis, innerside of the prepuce, oral cavity

Skin type found over the entire body; on palms and soles the cornified layer is much thicker

- Fig.47.7 Microstructure of nonkeratinizing and keratinizing skin 
- Fig.47.9 Microstructure of the skin from different body areas: $\mathbf{a}$ arm, $\mathbf{b}$ penis, and $\mathbf{c}$ small labia. Note the dense dermal structure with multiple vessels in a and lose collagen bundles in $\mathbf{b}$ and $\mathbf{c}$ with high similarity of penile and labial skin. Scale bar in all sections $500 \mu \mathrm{m}$. (Elastica-van-Gieson stainings; by courtesy of Dr. D. Jiang and Dr. Y. Rinkevich, Helmholtz Center Munich)
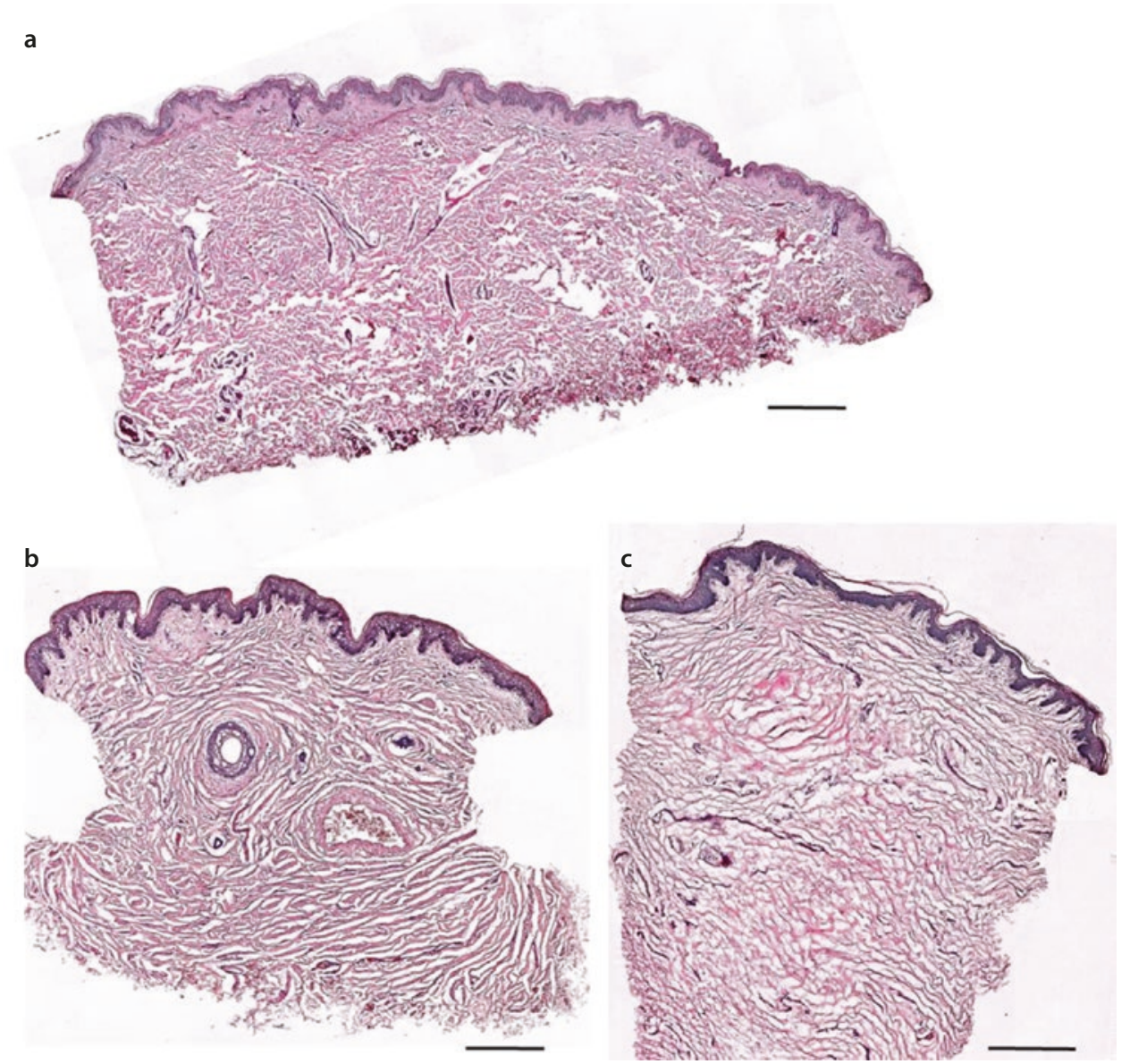

genital skin are equipped with a fast immune response to bacterial presence. By secreting antimicrobial peptides (AMPs) and defensins and with glandular mucous fluids, bacteria are held at a distance. The immune response is fast and so is the resolution with quick conversion of M1 to M2 macrophages and reduced expression of proinflammatory cytokines [38]. Upon injury, skin cells increase the interleukin (IL)-1 $\alpha$ production 15 -fold in comparison to vaginal epithelial cells with only threefold increase. IL-1 $\beta$ and tumor necrosis factor (TNF)- $\alpha$ were only secreted by cutaneous epithelia in contrast to mucous epithelial cells [9]. With regard to profibrotic mediators, TGF- $\beta$ is significantly elevated in normal skin keratinocytes but not in mucosal epithelia and without induction of fibrotic processes in the underlying connective tissue. In summary, the reduced inflammatory response of mucosal epithelia to injury is sufficient to ensure wound closure without inducing serious scarring.

\subsubsection{Hormonal Influences}

\subsubsection{Increased Aromatase Activity and Intracrine Estrogen Production}

Hormone responsivity of tissues has profound impact on wound healing. Estrogens accelerate wound closure whereas testosterone delays healing [10]. Skin is a major source of extraglandular sex steroid hormones that are produced from circulating dehydroepiandrosterone (DHEA, [24, 28]) (• Fig. 47.11). The intracellular enzyme aromatase converts DHEA downstream into the weaker estrogen Estrone or via testosterone into the more potent $17 \beta$-estradiol. Both estrogens act via the estrogen receptors (ERs) $\alpha$ and $\beta$, and stimulate keratinocyte and fibroblast migration [11]. In genital fibroblasts, aromatase expression is androgen dependent. Interestingly, estrogens stimulate fibroblast contractility without increasing alpha-smooth muscle actin expression or myofibroblast differentiation [31]. Upon 


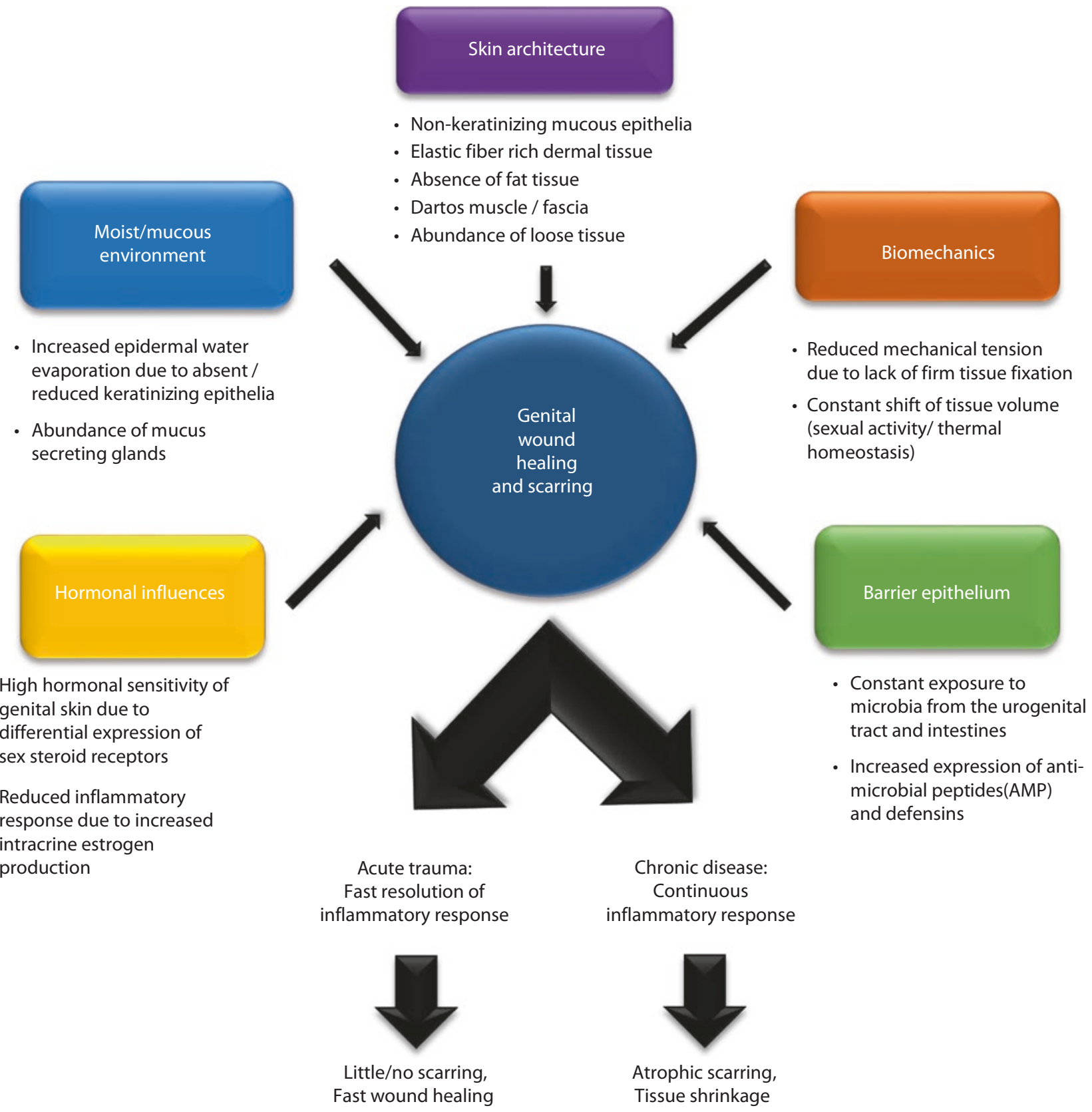

- Fig. 47.10 Factors that influence genital wound repair and differ from skin from other body regions

mechanical wounding, aromatase activity increases 400-fold in keratinocytes with increased intracellular bioavailability of estrogens. Testosterone reduces aromatase activity, albeit this effect is not present in case of low oxygen levels in tissues. Estrogens reduce the cellular inflammatory response via downregulation of the proinflammatory cytokine macrophage migration inhibitory factor (MIF) [6], by reduced TLR-4 mediated MAPK activation, by the reduction of macro- phage infiltration into wounds and by dampening the proinflammatory signaling of IL-6 and TNF- $\alpha$ [5]. Of note, estrogens are also important antioxidants that reduce cellular oxidative stress and apoptosis and increase keratinocyte migration and collagen synthesis by dermal fibroblasts [38]. In menopausal women, cutaneous estrogen insufficiency manifests by atrophic skin changes and a diminished defense against reactive oxygen species. 
- Fig. 47.11 Simplified description of intracrine sex steroid hormone production by skin cells. Dehydroepiandrosterone (DHEA) is released by the adrenal cortex and further processed directly into estrogens by aromatase or into testosterone by $17-\beta$-hydroxysteroid dehydrogenase (17- $\beta$-HSD). Estrone is reversibly oxidized into $17 \beta$-estradiol by $17 \beta$-OHSD. Testosterone can be either directly converted into the estrogen $17 \beta$-estradiol by aromatase or irreversibly converted into dihydrotestosterone by 5 - $\alpha$-reductase $(5 \alpha \mathrm{R})[39]$

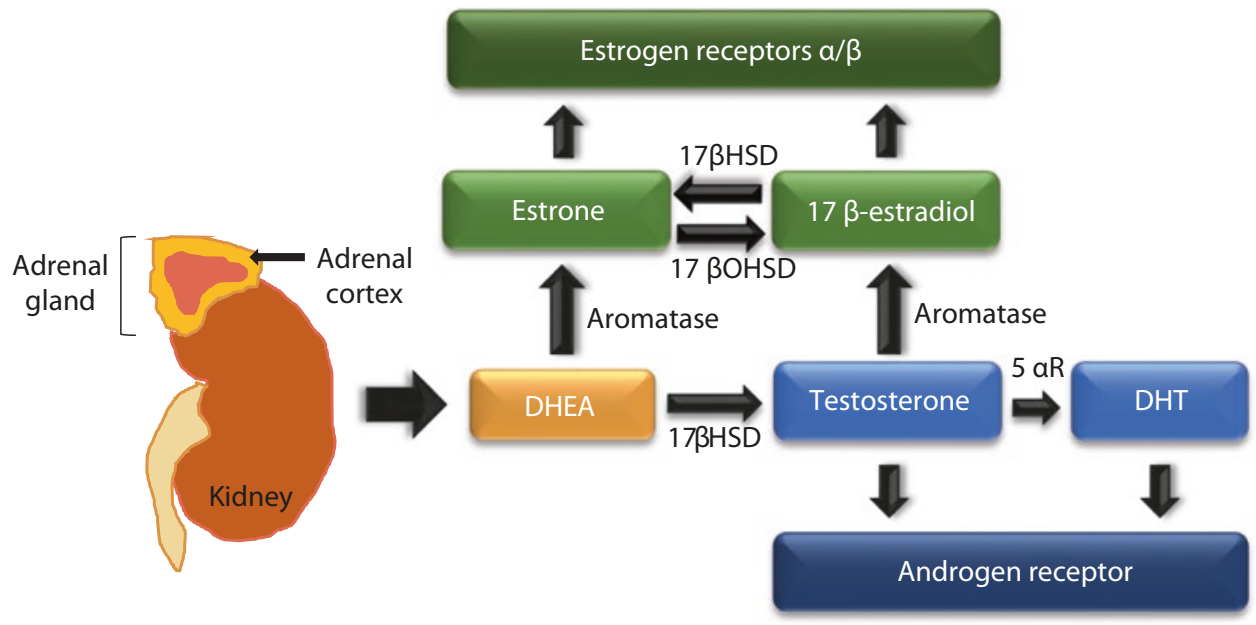

\subsubsection{Androgen and Estrogen Receptor Expression in Genital Skin}

Estrogens act via estrogen receptors and testosterone via androgen receptors (ARs) that are expressed by many cell types. For instance, AR expression differs between genital and nongenital skin with upregulation in genital fibroblasts. In general, it appears that sex steroid hormone expression is higher in stromal cells than in epithelial cells, implying higher responsiveness of fibroblasts to hormonal influences. Aside from receptor expression, the binding capacity and metabolism of sex steroid hormones differs between different skin regions. Testosterone binding capacity of the AR is higher in genital compared to nongenital skin cells [39] from both sexes - independently of age - and testosterone degradation is up to 30 times faster in genital skin compared with nongenital skin [30].

Sex hormone receptor expression in genital skin differs between prenatal and adult genital skin due to the terminal differentiation of the external genitalia that is dependent on hormonal influences. In fetal skin, ARs are very similarly expressed in both sexes with the absence of ARs on the preputial skin, penile shaft/labia minora, and scrotal skin/labia majora. ARs are expressed in the tissue of the glans and inner prepuce of both sexes and in the stromal tissue of the labia.

ER was present in fetal female genital skin except for labia minora and majora [16] and prominent ER staining was found in the entire developing fetal penis including skin, glans, inner prepuce, and stromal cells [4]. Interestingly, ARs and ERs were colocalized in penile tissues.

Less detailed information is available with regard to adult genital skin. In women, ARs are found in keratinocytes and fibroblasts of the labia majora and minora and in the adjacent extragenital skin. ER immunoposi- tivity was found in the labia minora and nongenital skin. There are no differences in sex hormone receptor expression between pre- and postmenopausal women. Progesterone receptors are not present in genital skin. In men, ARs were located to basal keratinocytes and stromal fibroblasts of the penile foreskin. No AR expression was found in nongenital cutaneous keratinocytes or fibroblasts but in fibroblasts of hair follicle papillae or in cells of pilosebaceous ducts and glands, skin structures that are influenced by androgens in their function and structure. The highest intensity of AR staining was noted in genital skin. ERs were similarly expressed in postnatal penile skin with localization to basal epithelia and stromal cells adjacent to the urethra and the urethra itself with age-dependent reduction [27]. Aromatase is not colocalized with estrogen receptors, and levels of aromatase, $\mathrm{ER} \alpha$, and $\mathrm{ER} \beta$ decrease with age [27].

In summary, ARs and ERs are highly expressed in genital skin in contrast to skin of other body areas with fast binding and degradation of testosterone or conversion into estrogen by increased aromatase activity. A summary of hormonal differences between genital skin and nongenital skin is given in $\bullet$ Table 47.2.

\subsection{Acute Wound Repair of Genital Skin After Trauma}

Depending on the type and severity of the injury, two main clinical symptoms characterize traumatized genitalia, namely enormous bleeding and swelling. When the hematoma resolves and the swelling disappears, wounds heal with almost no visible scarring even after major trauma. An example for invisible genital scarring is the fact that one-third of the male world population is circumcised [37] without any report of hypertrophic 
Table 47.2 Hormonal differences between genital skin and nongenital skin

Genital skin

Androgen receptor

Estrogen receptors

Testosterone

Estrogens

Aromatase fibroblasts conditions
Higher expression in labia majora and minora Upregulated in fibroblasts and basal keratinocytes Colocalization with ER

Highly expressed in penis and labia minora Restricted to basal keratinocytes and stromal

Expression decreases with age

Higher AR-binding capacity of testosterone 30 times faster degradation

Reduced effect on aromatase activity in low-oxygen

No conversion of $17 \beta$-estradiol into the weaker estrone Stimulate fibroblast contractility without alpha-smooth-muscle actin (ASMA) expression

Higher activity in fibroblasts with conversion of testosterone into $17 \beta$-estradiol

Dose-dependent reduced activity by testosterone

Aromatase expression androgen dependent
Nongenital skin

Only present in hair follicles and pilo-sebaceous duct keratinocytes

Low expression in extra-genital skin

Lower expression compared to vulva or vagina Expressed by keratinocytes and fibroblasts

Absence in skin appendages or blood vessels

Higher rate of conversion into DHT Higher 5- $\alpha$-reductase activity with irreversible formation of DHT

Threefold increased metabolism of $17 \beta$-estradiol into estrone

Expression in skin fibroblasts, keratinocytes of the outer root sheath and in terminal hair follicles and in cells of sebaceous glands and ducts

$A R$ androgen receptor, $E R$ estrogen receptor, $D H T$ dihydrotestosterone

scarring to the preputial skin. Despite major trauma after female genital mutilation/cutting, the genital skin heals uneventfully if the girl survives postinterventional bleeding and infection. Cutaneous genital infections are disastrous and can rapidly lead to septic conditions with high lethality. Fournier gangrene is one example of necrotizing fasciitis of the genital skin with a mortality rate of $80 \%$ without surgery [18]. Obviously, the loose architecture of genital skin provides optimal means for rapid subcutaneous bacterial spreading leading ultimately to multiple organ failure and death.

The aforementioned characteristics of the outer genitalia with regard to architecture, fixation, microenvironment, hormonal influences, and reduced inflammatory response orchestrate the fast resolution of the acute wound healing process with reduced scar formation. Albeit the apparently scar-free wound healing properties of genital skin, there is one exception. The ventral part of the prepuce ends in the so-called frenulum that is fixed to stromal tissue of the ventral side of the glans bridging to the penile shaft. In case of excessive tissue removal during circumcision, the frenulum can shrink and pull the glans in direction of the penile shaft that is painful, gives discomfort during erection, and can cause reduced sensation of the glans penis (• Fig. 47.12).

\subsection{Chronic Inflammatory Diseases of the External Genitalia and Tissue Fibrosis}

Several skin diseases with autoimmune background can affect the outer genitalia with chronic inflammation leading to tissue shrinkage and atrophy. Chronic lymphedema after tumor surgery and/or irradiation, with infectious background or due to congenital malformation of lymphatic organs, leads to tissue fibrosis and stiffening and to verruca-like epidermal changes in the long run. In the following, the most common chronic diseases and changes to the genital skin will be described in detail.

\subsubsection{Lichen Sclerosus et Atrophicus/ Balanitis Xerotica Obliterans}

Lichen sclerosus et atrophicus (LSC), also called balanitis xerotica obliterans in men, is the most common chronic dermatitis localized to the mucous membranes and skin of the genitalia. LSC is found in females and males with a ratio of up to 10:1 and has a double peak in females with occurrence in prepubertal and postmenopausal age. In men, LSC is the most common 
- Fig. 47.12 Examples for scar formation to the male genitalia. a Invisible scar after circumcision. Note differential pigmentation of the outer penile skin and the remaining inner part of the prepuce. $\mathbf{b}$ Scar after excessive circumcision with shortening and scarring of the frenulum (arrow). c Scrotal scar (arrow) after multiple excisions of silicone granuloma and subcutaneous fibrotic tissue

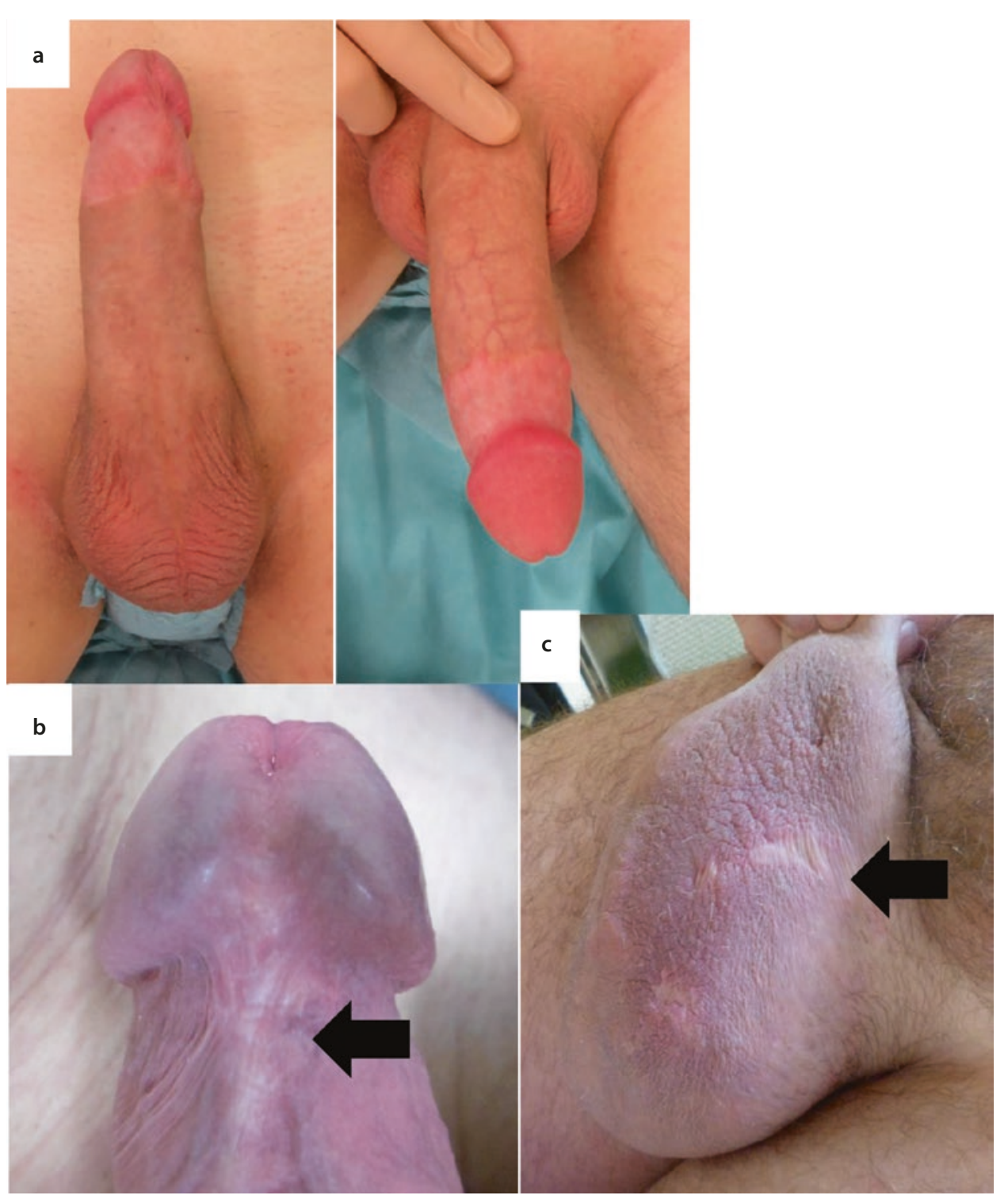

cause of acquired phimosis [3] and affects the glans and the prepuce (- Fig. 47.13). Typical symptoms are a thickening of the foreskin that impairs retraction. Whitish plaques can extend over the entire glans with affection of the urethral meatus followed by stenosis and voiding problems. In females, the anogenital area is frequently affected forming an 8-shaped efflorescence around the vulva and the anal orifice with opaque plaques and papules. In chronic disease, these atrophic lesions can lead to a complete destruction of the vulva with resorption of the small labia, narrowing of the vaginal introitus and burying of the clitoris. The patients' quality of life is severely reduced due to chronic pruritus, pain, and obstipation resulting from painful defecation in women and painful erection and hygienic problems in men. Of note, LSC is associated with squamous cell carcinoma formation in $5 \%$ of women [17] and up to $30 \%$ of men [3]. Other LSCassociated diseases comprise autoimmune thyroiditis, vitiligo, or pernicious anemia. The etiology of LSC is not fully understood. An autoimmune origin with Tand B-cell-driven response to a yet unknown antigen is discussed because dense T-lymphocytic infiltrates with concomitant vasculitis and extensive tissue destruction are found in LSC-tissue sections. The glycoprotein extracellular matrix protein 1 (ECM 1) has been targeted as putative autoantigen because the symptoms of the autosomal recessive disorder lipoid proteinosis resemble acquired LSC with thickening and scarring of skin and mucosa [2]. Another related dermatosis, the Lichen planus, presents with similar symptoms and etiology that makes the initial differentiation between lichen sclerosus and lichen planus difficult [35]. 


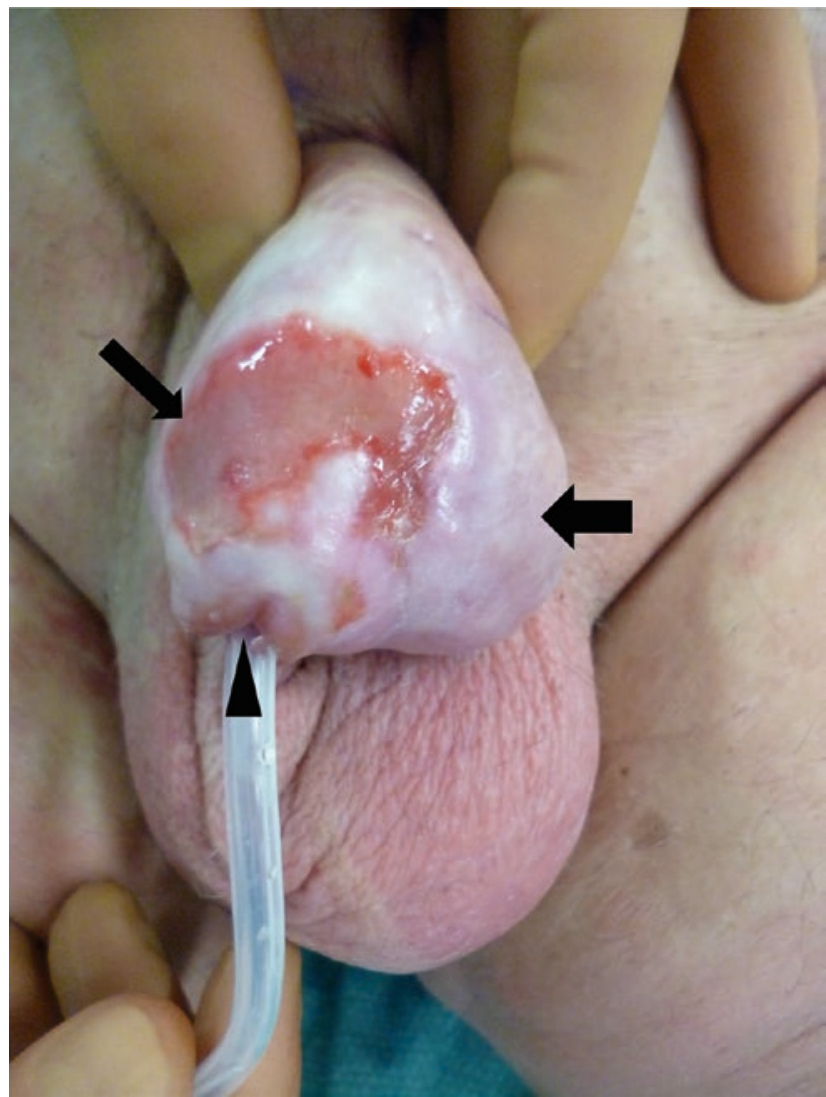

- Fig. 47.13 Patient with Lichen sclerosus et atrophicus to the penile glans and after several circumcisions and reconstruction of a buried penis. Note central ulceration (thin arrow) surrounded by opaque and shiny skin changes of the glans including meatal stenosis (arrowhead) and granuloma formation (thick arrow)

\subsubsection{Behçet's Disease}

Aphthous stomatitis (oral ulcers) and genital ulcers are common features of Behçet's disease. The etiology of the autoimmune vasculitis is unknown. The most common site for genital ulcer formation is the scrotum in men and the big labia in women. Interestingly, scrotal and big labia ulcers heal with normal, nonhypertrophic scarring whereas skin lesions on the small labia heal without scars similar to oral ulcers [22].

\subsubsection{Chronic Inflammation due to Foreign Body Reaction}

The size of the penis is of central importance for many men who build their self-confidence on the penile length. In that context it is not surprising that a plethora of different substances were used for penile enlargement over centuries. Vaseline, paraffin, liquid mercury, silicone (- Figs. 47.12c and 47.14), or cod liver oil were injected in to the scrotum or under the penile skin for girth enhancement with catastrophic complications such as granuloma formation, infections, swelling, and local tissue necrosis [33]. Alternatively polymethylmethacrylate (PMMA) microspheres or autologous fat are used as fillers or silicone implants for permanent enlargement [19, 20]. The placement of permanent, alloplastic foreign body material in an environment populated by a variety of commensal microbes is risky due to the inherent danger of infection. In case of granuloma, tissue necrosis, or implant infection, the foreign material must be removed with subsequent tissue loss. Foreign body materials can initiate a chronic inflammatory process with cutaneous thickening and subcutaneous tissue fibrosis leading ultimately to a shrinkage of the entire penile shaft. Details of the surgical treatment after foreign body injection are shown in - Fig. 47.14.

\subsubsection{Congenital and Acquired Genital Lymphedema and Tissue Fibrosis}

Lymphedema is defined as low- $(<1 \mathrm{~g} / 100 \mathrm{ml})$ or high$(>1 \mathrm{~g} / 100 \mathrm{ml})$ protein fluid retention in the interstitial space [8]. Congenital malformation of lymphatic vessels can cause chronic lymphedema. Acquired lymphedema occurs after surgery (• Fig. 47.15) for various reasons (cancer, gangrene, foreign bodies, etc.), irradiation, or filariasis. The swelling is due to an imbalance of the production and absorption, including drainage of the lymph that can be caused by an obstruction, disruption, or insufficiency of the lymph vessels. Chronic lymphedema affects the surrounding tissue with fibrosis and the skin with rhagades and recurrent infections, blister formation, wart-like epidermal excrescences, and scarring.

\subsection{Treatment of Genital Wounds and Scars}

The manifold the causes for wounding and scarring to the genitalia are, the diverging are the treatments as well. The choice of the appropriate surgical technique is orientated on the depth, magnitude, and location of the defect and the quality of the surrounding tissue. Needless to say that the delicate genital anatomy of both sexes and the variety of tissue defects or scars that can extend over to adjacent body areas require highly skilled surgeons with expertise in reconstruction of the genitalia. Aside from defect closure, restoration of the voiding and sexual function are central to each reconstructive procedure and require often an interdisciplinary setting. 

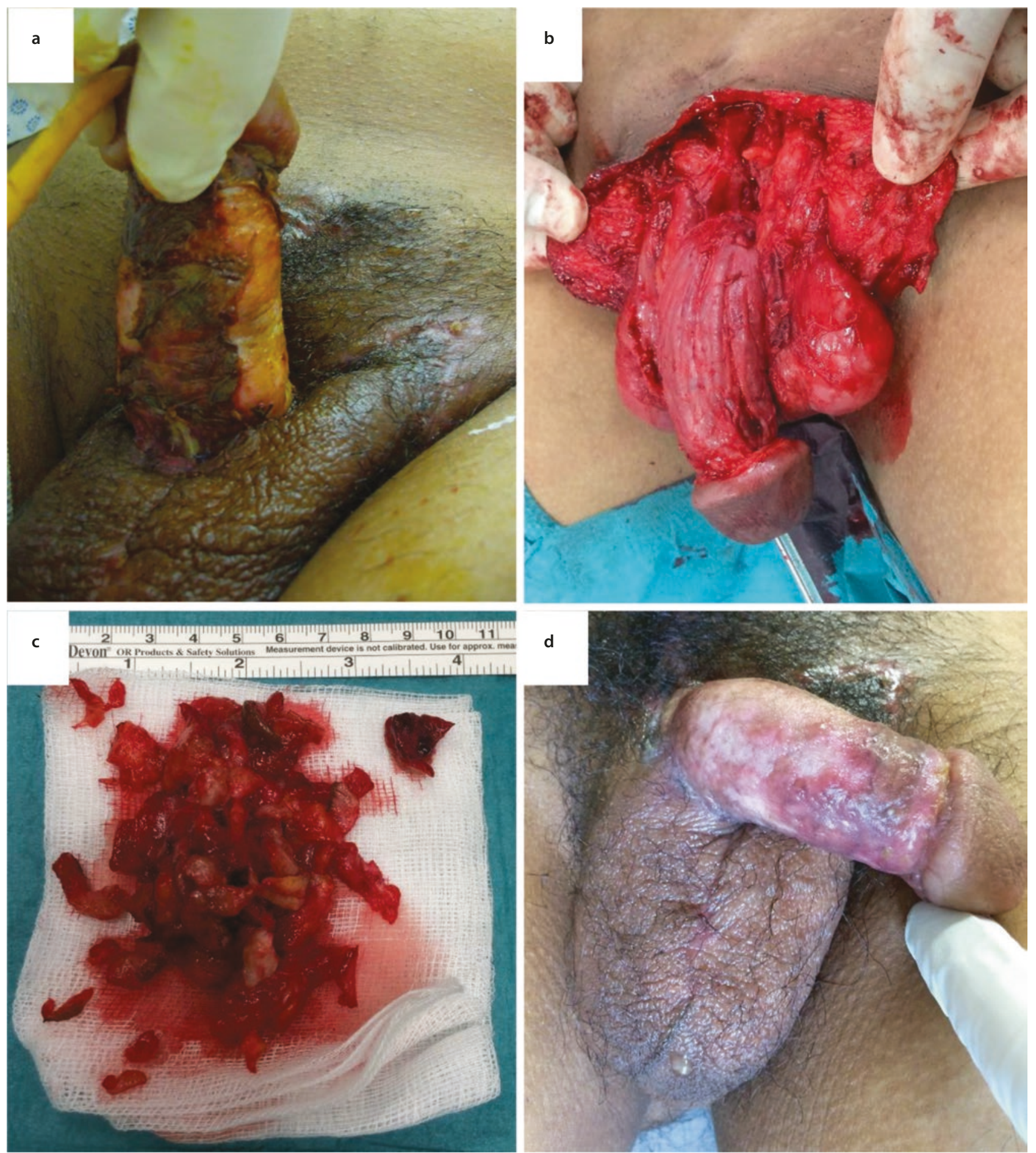

- Fig. 47.14 Penile skin necrosis after silicone oil injection. a Tissue necrosis over the entire penile shaft preoperatively. b, c Intraoperative situs $\mathbf{b}$ after meticulous excision of all foreign body material

and granuloma c. d Postoperative result after full-thickness skin grafting with epidermal thickening and hypopigmentation 6 weeks after grafting 

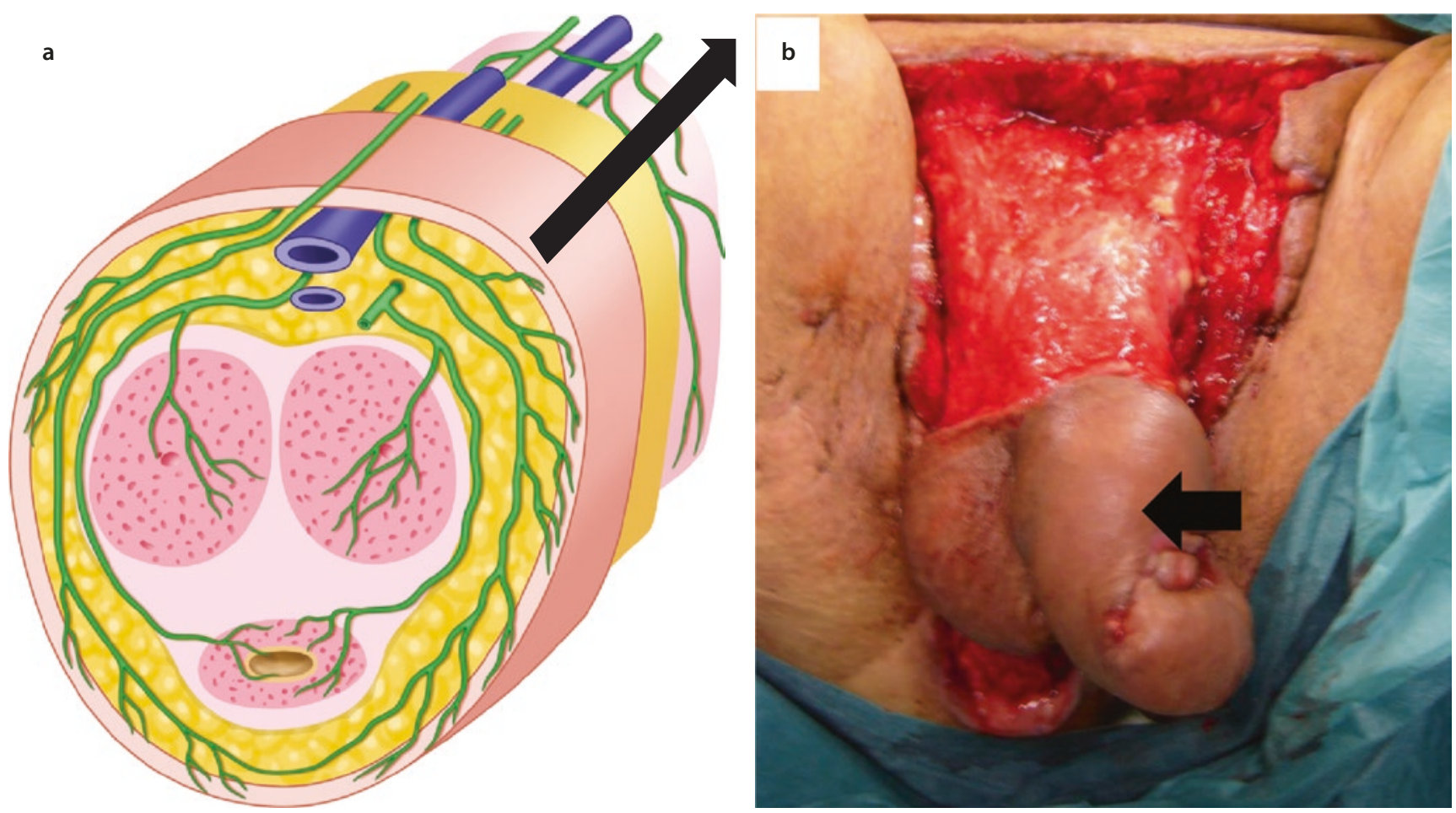

- Fig. 47.15 Penile lymphedema a Penile lymphatic vessels and lymph drainage on the dorsal side of the penile shaft (arrow). b Fournier gangrene on the base of a chronic acne inversa with massive tissue resection of the prepubic and groin area after necrotizing

infection with a multiresistant Staphylococcus aureus and different enterobacteriaceae. Note massive swelling of the penile shaft (arrow) with burying of the glans due to loss of dorsal lymphatic vessels and drainage pathways after debridement

\subsubsection{Treatment of Acute Wounds and Tissue Defects}

Small acute wounds and tissue defects are commonly closed primarily due to the abundance, elasticity, and loose fixation of the genital skin and tissue. For instance, primary closure of scrotal defects after up to $50 \%$ tissue loss is feasible, otherwise local or distant flaps (e.g., bilateral gracilis flaps; - Fig. 47.16) or skin grafts are used to reconstruct the scrotal sac [18]. Superficial skin loss to the penile glans recovers by conservative treatment, and deeper tissue defects need skin grafting, for example, with oral mucosa or thin split-thickness skin [34]. Penile shaft defects can be elegantly closed using preputial flaps in case the patient is not circumcised. Otherwise, split-thickness or full-thickness skin grafts are the current state-of-the-art for penile shaft reconstruction. Drawback of free skin grafts is the lack of cutaneous elasticity and sensation. In case of abundant scrotal tissue, local neurovascular flaps (e.g., midline raphe scroti artery, MiRA-flap) can restore - at least in part-tissue texture and sensation [26].

The reconstruction of the female genitalia is similar as in men with primary closure of small lesions and flap surgery in case of larger tissue losses. An elegant procedure for reconstruction of the big labia is the anterior obturator artery perforator flap (aOAP) that is harvested from the groin area [29]. Interestingly, the flap tissue heals with minimal scarring once it is transferred to the vulva in contrast to its harvest site in the groin that is prone to hypertrophic scarring (personal communication with Prof. Dr. Uwe von Fritschen, Desert Flower Center, Helios Klinikum Emil von Behring, Berlin).

\subsubsection{Treatment of Genital Wounds and Scars After Burn Injury}

The golden standard for treatment of partial-thickness (deep second degree) and full-thickness (third degree) burns is debridement of the necrotic tissue with skin grafting. Due to its high regenerative potential, a more conservative approach is the current clinical practice for genital skin until full demarcation of the necrotic tissue. As mentioned earlier, the genitals are capable of 

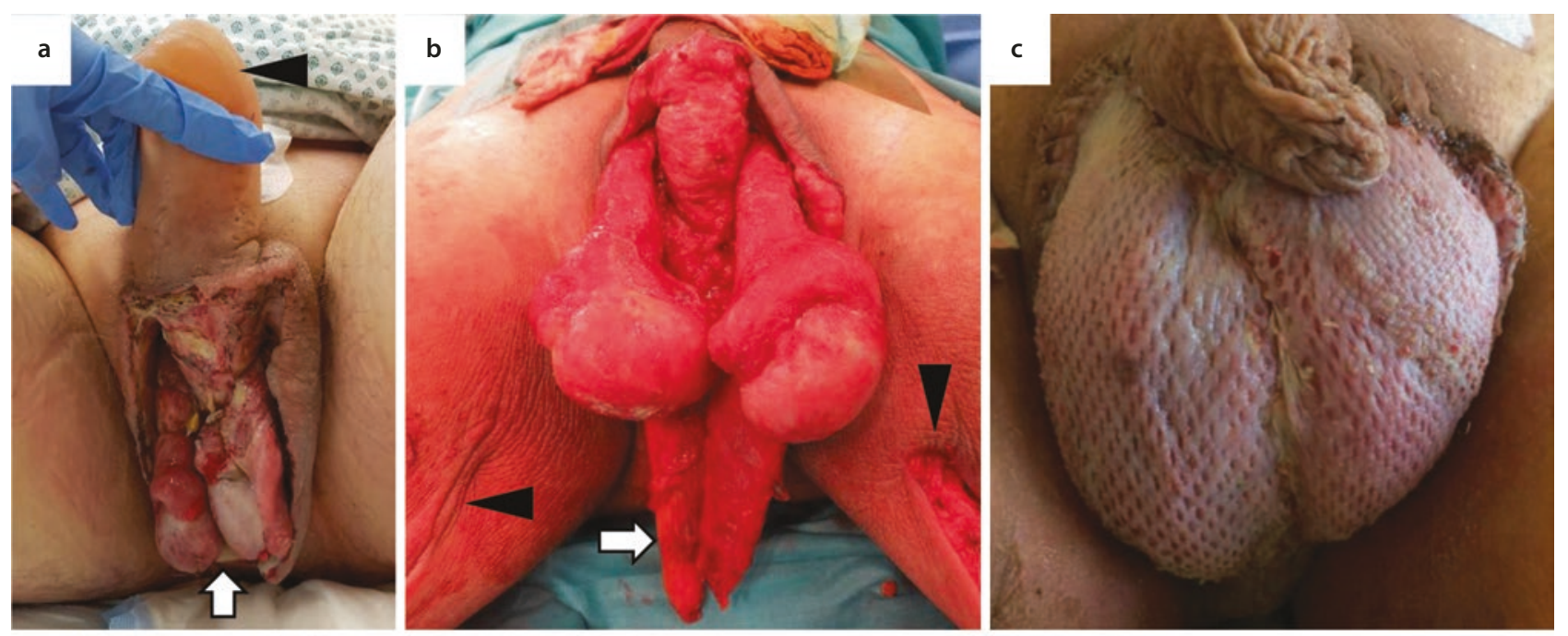

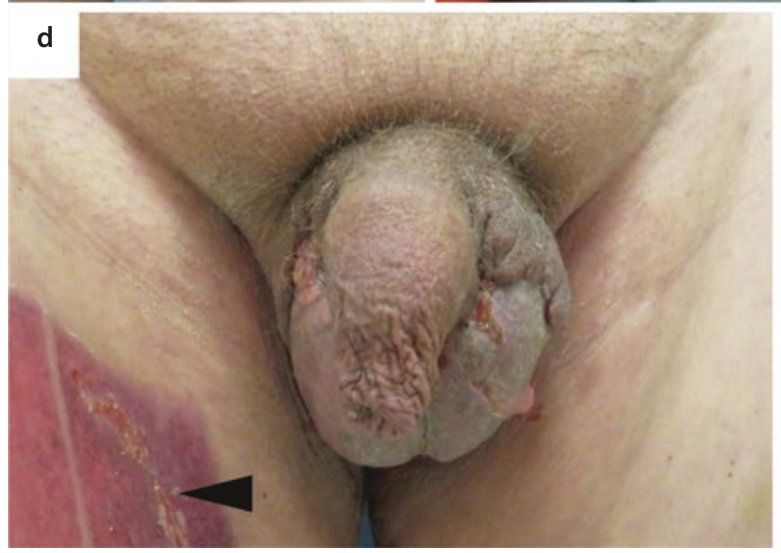

- Fig. 47.16 Plastic-reconstructive surgery of the scrotum with bilateral gracilis muscle flaps covered by a split-thickness skin graft. a Preoperative site with almost complete loss of the scrotal tissue. Both testes are exposed (white arrow) with lymphedematous swelling of the penis (arrowhead). b Intraoperative situs after debridement. Both gracilis muscles (white arrow) are mobilized and rotated into

compensating for rather large tissue losses with only minor scar formation [15]. In contrast, severe scarring and scar contractures are common to the groin and perineal area that can impair the movement of the lower extremities (- Figs. 47.2 and 47.3). After scar excision, local skin flaps, for example, Z-plasties, are usually used for wound closure and tension release. In case of insufficient local tissue, distant, pedicled, or free flaps with microvascular anastomosis are standard procedures and belong to the repertoire of a plastic-reconstructive surgeon (• Fig. 47.17). For further detailed information, the recently published textbooks for genital [25] or burn [13] reconstructive surgery are recommended. the defect by tunneling underneath the perineal crease. Harvest areas are depicted with arrowheads. c Postoperative site after 1 week with almost complete skin graft take. d Situation after 3 weeks with little scarring and a skin texture resembling the natural scrotal appearance. Note split-thickness harvest site to the right thigh (arrowhead)

\subsubsection{Gender Reassignment Surgery}

Genital gender reassignment surgery comprises the formation of a female vulva, including big and small labia, a clitoris with a clitoral hood and a vagina in male-tofemale transsexuals and the formation of a penoid with functional elongation of the urethra and a scrotum in female-to-male transsexuals. Highly specialized surgeons perform these extraordinary procedures in an interdisciplinary context with astonishing results. Notably scarring is minimal despite extensive surgical intervention to the genitalia with relocation of ontogenetically homologous entities. My profound fascination for absent or minimal genital scarring derives from patients after gender reassignment surgery (• Fig. 47.18). 


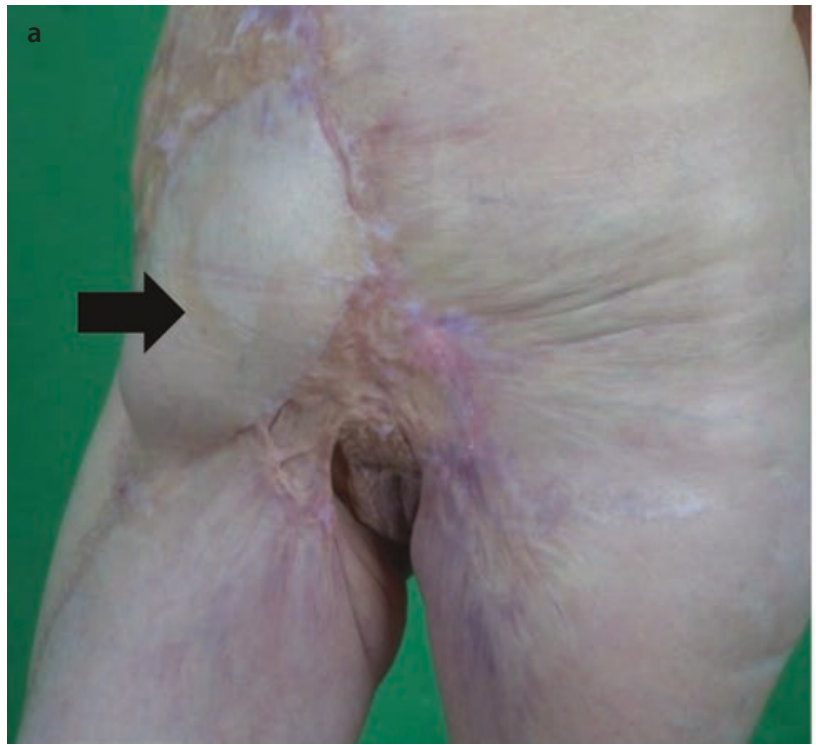

- Fig. 47.17 Scar contractures to the inguinal and perineal region after burn injury. a Preoperative situs with scar contractures spanning over both groins that impair the range of motion of both legs. Of note, the genital area, including the big labia, is devoid of scar-

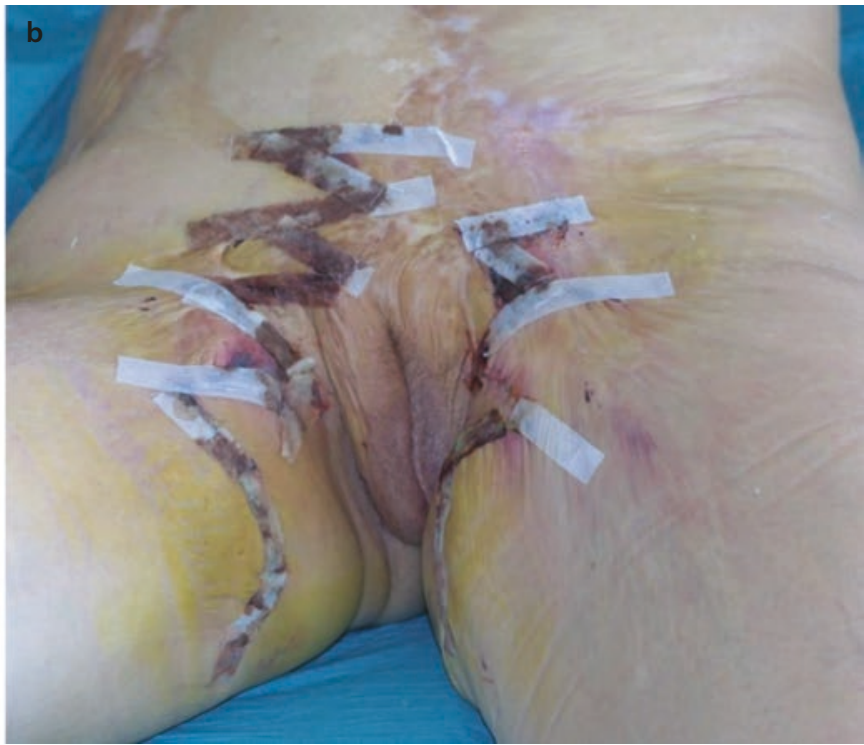

ring. Previous reconstructive surgery included local tissue transfer for scar release to the right groin (arrow). b Postoperative situs after multiple Z-plasties

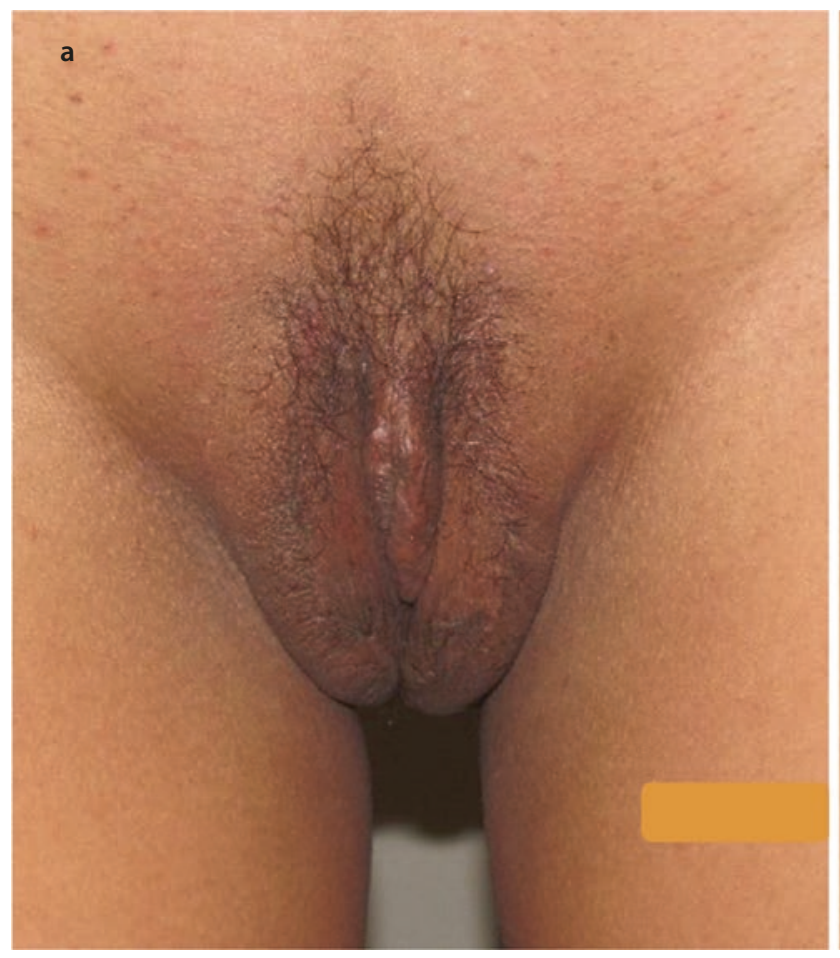

- Fig. 47.18 Male-to-female transsexual patient after genital reassignment surgery. Note construction of all vulvar structures with big and small labia, a clitoris covered completely by the clitoral prepuce

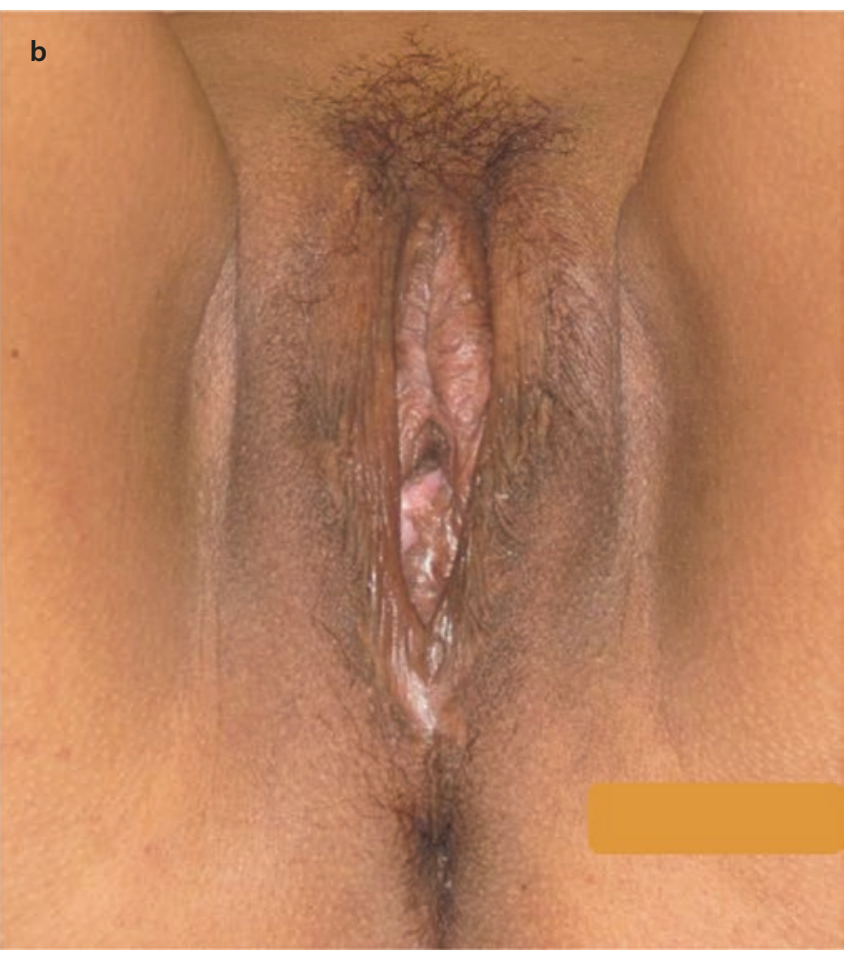

and the vaginal entrance. a. ventral aspect, $\mathbf{b}$. caudal aspect (By courtesy of Dr. Jürgen Schaff, PSC Munich) 


\subsubsection{Treatment of Chronic Genital Skin Diseases}

Chronic genital ulcers can originate from autoimmune diseases, infections, pressure sores, etc. Describing details on the systemic rheumatologic treatment of autoimmune disorders is beyond the scope of this chapter. More information on diagnosis and therapy of dermatologic autoimmune disorders is provided in excellent reviews [7, 32].

LSC in women responds well to topical corticosteroid ointments whereas phimoses in men require surgical intervention. Circumcision with complete removal of the penile foreskin is the gold standard that leads to relapse-free recovery from $\operatorname{LSC}[3,7]$.

\subsubsection{Lymphedema Treatment}

Depending on the underlying cause of noninfectious genital lymphedema, the treatment is primarily conservative with a complex decongestive physiotherapy (CDP), according to Földi [8]. To ensure permanent lymphatic drainage, compression therapy is recommended not only in patients with lymphedema but also in patients after genital reconstruction. Surgical intervention in secondary genital lymphedema is controversially discussed and should be limited to selected patients in the hands of experienced surgeons and physiotherapists $[23,36]$.
The treatment of filariasis is antimicrobial; in case of genital elephantiasis, surgical removal of penile and scrotal tissue is indicated for debulking although clinical studies on the postsurgical outcome are scarce [21].

\subsection{Postoperative Management for Scar Prevention}

Postoperative excessive scarring of the genitalia is rare and limited to free partial-thickness skin grafts to the penile shaft. In contrast, hypertrophic scarring and scar contractures are common to the perineal and inguinal area with postoperative compression therapy and mobilizing physiotherapy being imperative. With regard to the genitals, lymphedema formation is more common and an issue for intensive postoperative care. Standard or tailor-made individual compression garments are available and recommended for 3-6 months. Compression panties for women are available in different sizes. With regard to male compression therapy, the issue is more problematic due to difficulties in handling penile compression stockings and the fixation to the penile base. Our group has developed such a penile compression stocking in cooperation with highly qualified orthopedic technicians who produce individually tailored pressure garments for men after skin grafts or flap surgery with postoperative lymphedematous swelling. After a short training period, all men were capable of handling the stocking by themselves (• Fig. 47.19).
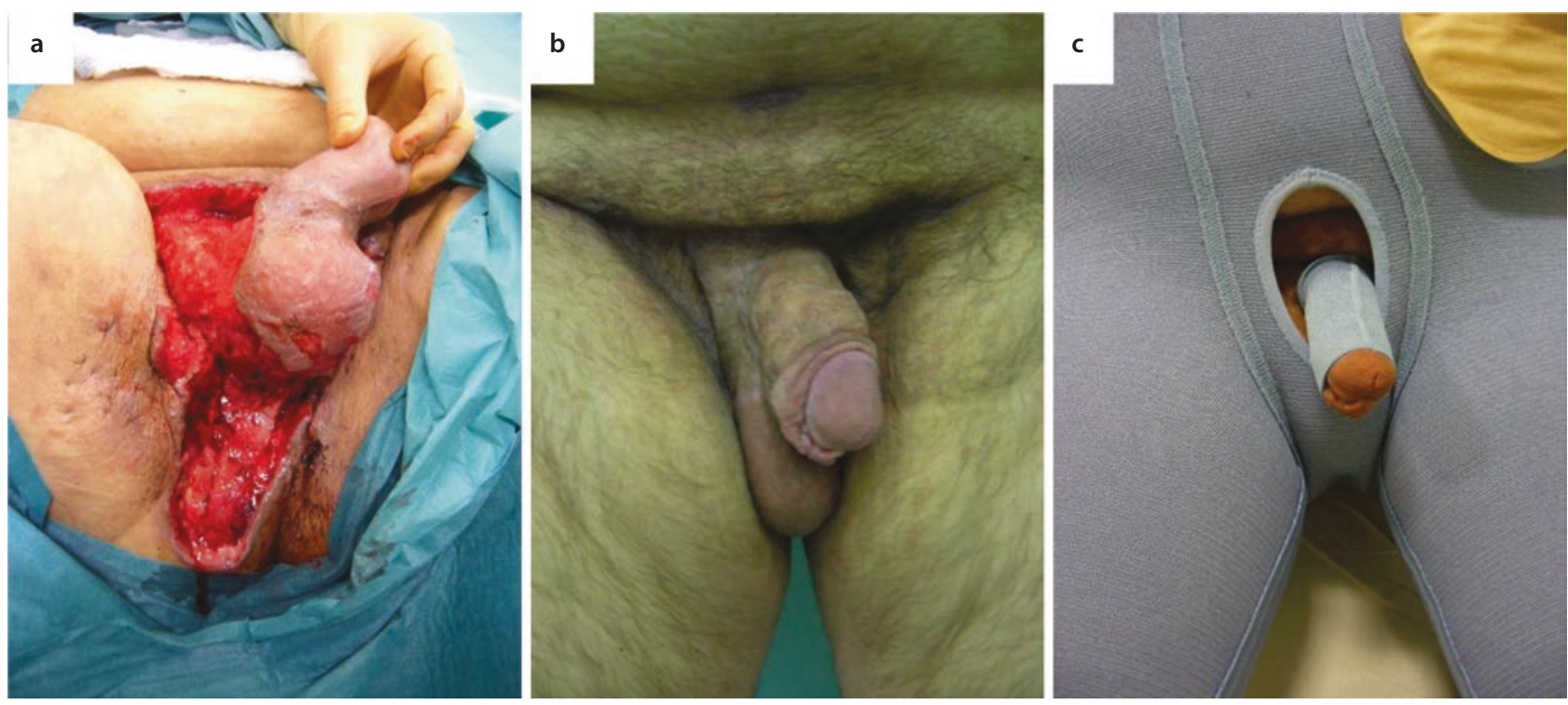

- Fig. 47.19 Postoperative treatment after reconstruction of a genital and perineal defect after Fournier gangrene. a Preoperative site after multiple debridements. b Postoperative situation 4 weeks after defect closure with split-thickness skin grafts. c Adjuvant treat- ment with tailor-made pressure garments to prevent excessive scarring. Note separate compression panty for the perineal area and a tailor-made stocking for the penile shaft 
We recommend the prescription of at least two pairs of garments to ensure daily changes and washing for better hygiene.

\subsection{Conclusion}

Hypertrophic scarring to the genitalia is uncommon, possibly due to the high regenerative potential of genital skin, the abundance and elasticity of the local tissue, and the rapid and reduced immune response to traumatic events. Chronic inflammatory diseases such as lichen sclerosus et atrophicus or chronic lymphedema lead to tissue fibrosis with epidermal thickening and to a shrinkage and atrophy with complete destruction of the genitalia in the long run. In contrast to the genital skin, hypertrophic scarring and scar contractures are frequently seen in body areas adjacent to the genitalia, for example, the groin or the perineal crease. The reconstructive procedures for scar release or tissue defect coverage should aim not only at defect closure but also at the functional restoration of micturition and sexuality and should exclusively be performed by experienced specialists preferably in an interdisciplinary setting.

\section{Take-Home Messages}

- Genital skin wounds heal fast and with almost invisible scarring.

- The anatomical microstructure of genital skin differs in its architecture and elasticity to skin from other body sites.

- Extensive tissue loss can be compensated-in part - due to the abundance of genital skin.

- The inflammatory response of genital skin is adapted to the permanent microbial colonialization with fast-onset and quick resolution.

- Androgen and estrogen receptors are highly expressed in genital skin. Genital wound repair benefits from hormonal responsiveness and increased presence of sex steroid hormones due to intracrine production by skin cells.

- Chronic inflammatory conditions caused by autoimmune disorders, infections, or foreign material can lead to severe tissue fibrosis followed by shrinkage and destruction of the outer genitalia.

- Chronic lymphedema manifests in enormous swelling of the outer genitalia with long-term tissue fibrosis and wart-like epidermal changes.

- Reconstruction of tissue defects or scar contractures should include the functional restoration of micturition and sexuality.

- Reconstructive interventions to the outer genitalia are complex and delicate and should exclusively be performed by experienced surgeons specialized in genital surgery.

\section{References}

1. Balzano FL, Hudak SJ. Military genitourinary injuries: past, present, and future. Transl Androl Urol. 2018;7:646-52.

2. Chan I, Liu L, Hamada T, Sethuraman G, McGrath JA. The molecular basis of lipoid proteinosis: mutations in extracellular matrix protein 1. Exp Dermatol. 2007;16:881-90.

3. Clouston D, Hall A, Lawrentschuk N. Penile lichen sclerosus (balanitis xerotica obliterans). BJU Int. 2011;108 Suppl 2:14-9.

4. Crescioli C, Maggi M, Vannelli GB, Ferruzzi P, Granchi S, Mancina R, Muratori M, Forti G, Serio M, Luconi M. Expression of functional estrogen receptors in human fetal male external genitalia. J Clin Endocrinol Metab. 2003;88:1815-24.

5. Crompton R, Williams H, Ansell D, Campbell L, Holden K, Cruickshank S, Hardman MJ. Oestrogen promotes healing in a bacterial LPS model of delayed cutaneous wound repair. Lab Investig. 2016;96:439-49.

6. Emmerson E, Campbell L, Ashcroft GS, Hardman MJ. Unique and synergistic roles for 17 beta-estradiol and macrophage migration inhibitory factor during cutaneous wound closure are cell type specific. Endocrinology. 2009;150:2749-57.

7. Fistarol SK, Itin PH. Diagnosis and treatment of lichen sclerosus: an update. Am J Clin Dermatol. 2013;14:27-47.

8. Földi M, Földi E. Földi's textbook of lymphology. San Francisco: Elsevier; 2012.

9. Gallant-Behm CL, Du P, Lin SM, Marucha PT, Dipietro LA, Mustoe TA. Epithelial regulation of mesenchymal tissue behavior. J Invest Dermatol. 2011;131:892-9.

10. Gilliver SC, Ashcroft GS. Sex steroids and cutaneous wound healing: the contrasting influences of estrogens and androgens. Climacteric. 2007;10:276-88.

11. Gilliver SC, Ashworth JJ, Ashcroft GS. The hormonal regulation of cutaneous wound healing. Clin Dermatol. 2007;25: 56-62.

12. Harpole BG, Wibbenmeyer LA, Erickson BA. Genital burns in the national burn repository: incidence, etiology, and impact on morbidity and mortality. Urology. 2014;83:298-302.

13. Herndon DN, editor. Total burn care. Philadelphia: Saunders Elsevier; 2018.

14. Isbir D, Cedidi C. Acne inversa inguinalis. In: Mirastschijski U, Remmel E, editors. Intimchirurgie. Berlin: Springer; 2019. p. 243-51.

15. Ismail Aly ME, Huang T. Management of burn injuries of the perineum. In: Herndon D, editor. Total burn care. London: Elsevier; 2018. p. 609-17.

16. Kalloo NB, Gearhart JP, Barrack ER. Sexually dimorphic expression of estrogen receptors, but not of androgen receptors in human fetal external genitalia. J Clin Endocrinol Metab. 1993;77:692-8.

17. Kirtschig G. Lichen sclerosus-presentation, diagnosis and management. Dtsch Arztebl Int. 2016;113:337-43.

18. Lehnhardt M, Wallner C, Daigeler A. Reconstruction of the male genitals after Fournier gangrene. In: Mirastschijski U, Remmel E, editors. Intimchirurgie. Berlin: Springer; 2019. p. 253-63.

19. Lemperle G, Casavantes L. Penisvergrößerung durch Injektion von PMMA-Mikrosphären. In: Mirastschijski U, Remmel E, editors. Intimchirurgie. Berlin: Springer; 2019. p. 79-89.

20. Lemperle G, Elist JJ, Jethon C. Penisvergrößerung mit dem Penuma-Silikon-Implantat. In: Mirastschijski U, Remmel E, editors. Intimchirurgie. Berlin: Springer; 2019. p. 69-78.

21. Lim KH, Speare R, Thomas G, Graves P. Surgical treatment of genital manifestations of lymphatic filariasis: a systematic review. World J Surg. 2015;39:2885-99.

22. Mat MC, Goksugur N, Engin B, Yurdakul S, Yazici H. The frequency of scarring after genital ulcers in Behcet's syndrome: a prospective study. Int J Dermatol. 2006;45:554-6. 
23. Mcdougal WS. Lymphedema of the external genitalia. J Urol. 2003;170:711-6.

24. Mills SJ, Ashworth JJ, Gilliver SC, Hardman MJ, Ashcroft GS. The sex steroid precursor DHEA accelerates cutaneous wound healing via the estrogen receptors. J Invest Dermatol. 2005;125:1053-62.

25. Mirastschijski U, Remmel E. Intimchirurgie. Berlin: Springer; 2019.

26. Mirastschijski U, Schwenke C, Schmiedl A. Plastic-surgical reconstruction of the male genitals. In: Mirastschijski U, Remmel E, editors. Intimchirurgie. Berlin: Springer; 2019. p. 189-206.

27. Mowa CN, Jesmin S, Miyauchi T. The penis: a new target and source of estrogen in male reproduction. Histol Histopathol. 2006;21:53-67.

28. Nelson LR, Bulun SE. Estrogen production and action. J Am Acad Dermatol. 2001;45:S116-24.

29. O'dey DM, Bozkurt A, Pallua N. The anterior Obturator Artery Perforator (aOAP) flap: surgical anatomy and application of a method for vulvar reconstruction. Gynecol Oncol. 2010;119:526-30.

30. Pinsky L, Finkelberg R, Straisfeld C, Zilahi B, Kaufman M, Hall G. Testosterone metabolism by serially subcultured fibroblasts from genital and nongenital skin of individual human donors. Biochem Biophys Res Commun. 1972;46:364-9.

31. Pomari E, Dalla Valle L, Pertile P, Colombo L, Thornton MJ. Intracrine sex steroid synthesis and signaling in human epidermal keratinocytes and dermal fibroblasts. FASEB J. 2015;29:508-24.

32. Saccucci M, Di Carlo G, Bossu M, Giovarruscio F, Salucci A, Polimeni A. Autoimmune diseases and their manifestations on oral cavity: diagnosis and clinical management. J Immunol Res. 2018;2018:6061825.

33. Schill S, Panfilov DE, Mirastschijski U. Intimchirurgie beim Mann. In: Mirastschijski U, Remmel E, editors. Intimchirurgie. Berlin: Springer; 2019. p. 49-68.

34. Schwenke C, Melchior S. Peniskarzinom aus uro-onkologischer Sicht. In: Mirastschijski U, Remmel E, editors. Intimchirurgie. Berlin: Springer; 2019. p. 207-15.

35. Terlou A, Santegoets LA, Van Der Meijden WI, HeijmansAntonissen C, Swagemakers SM, Van Der Spek PJ, Ewing PC,
Van Beurden M, Helmerhorst TJ, Blok LJ. An autoimmune phenotype in vulvar lichen sclerosus and lichen planus: a Th1 response and high levels of microRNA-155. J Invest Dermatol. 2012;132:658-66.

36. Torio-Padron N, Stark GB, Foldi E, Simunovic F. Treatment of male genital lymphedema: an integrated concept. J Plast Reconstr Aesthet Surg. 2015;68:262-8.

37. Who. Male circumcision. Global trends and determinants of prevalence, safety and acceptability. In: Data ILC-i-P, editor. UNAIDS/07.29E/JC1320E. Geneva: WHO Press; 2007.

38. Wilkinson HN, Hardman MJ. The role of estrogen in cutaneous ageing and repair. Maturitas. 2017;103:60-4.

39. Zouboulis CC, Chen WC, Thornton MJ, Qin K, Rosenfield R. Sexual hormones in human skin. Horm Metab Res. 2007;39:85-95.

\section{Further Reading}

Ismail Aly ME, Huang T. Management of burn injuries of the perineum. In: Herndon D, editor. Total burn care. London: Elsevier; 2018. p. 609-17.

Mills SJ, Ashworth JJ, Gilliver SC, Hardman MJ, Ashcroft GS. The sex steroid precursor DHEA accelerates cutaneous wound healing via the estrogen receptors. J Invest Dermatol. 2005;125:1053-62.

Mirastschijski U, Remmel E. Intimchirurgie. Berlin: Springer; 2019.

Mowa CN, Jesmin S, Miyauchi T. The penis: a new target and source of estrogen in male reproduction. Histol Histopathol. 2006;21:53-67.

Nelson LR, Bulun SE. Estrogen production and action. J Am Acad Dermatol. 2001;45:S116-24.

Terlou A, Santegoets LA, Van Der Meijden WI, HeijmansAntonissen C, Swagemakers SM, Van Der Spek PJ, Ewing PC, Van Beurden M, Helmerhorst TJ, Blok LJ. An autoimmune phenotype in vulvar lichen sclerosus and lichen planus: a Th1 response and high levels of microRNA-155. J Invest Dermatol. 2012;132:658-66.

Torio-Padron N, Stark GB, Foldi E, Simunovic F. Treatment of male genital lymphedema: an integrated concept. J Plast Reconstr Aesthet Surg. 2015;68:262-8.

Zouboulis CC, Chen WC, Thornton MJ, Qin K, Rosenfield R. Sexual hormones in human skin. Horm Metab Res. 2007;39:85-95.

Open Access This chapter is licensed under the terms of the Creative Commons Attribution 4.0 International License (http://creativecommons. $\mathrm{org} /$ licenses/by/4.0/), which permits use, sharing, adaptation, distribution and reproduction in any medium or format, as long as you give appropriate credit to the original author(s) and the source, provide a link to the Creative Commons license and indicate if changes were made.

The images or other third party material in this chapter are included in the chapter's Creative Commons license, unless indicated otherwise in a credit line to the material. If material is not included in the chapter's Creative Commons license and your intended use is not permitted by statutory regulation or exceeds the permitted use, you will need to obtain permission directly from the copyright holder.

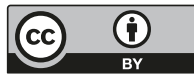

